\title{
is Research Square \\ Elicitor-induced phenolic acids accumulation in Salvia virgata Jacq. hairy root cultures
}

Parvaneh Abrishamchi ( $\square$ abrisham@um.ac.ir)

Biology Department, Faculty of Science, Ferdowsi University of Mashhad https://orcid.org/0000-00020720-5880

\section{Samaneh Attaran Dowom}

Ferdowsi University of Mashhad Faculty of Sciences

\section{Tayebeh Radjabian}

Shahed University

\section{Seyed Alireza Salami}

Tehran University: University of Tehran

\section{Original Article}

Keywords: Agrobacterium rhizogenes, Caffeic acid, Hairy root, Rosmarinc acid, Salvia virgata Jacq., Salvianolic acid $A$.

Posted Date: April 16th, 2021

DOl: https://doi.org/10.21203/rs.3.rs-169177/v1

License: (c) (i) This work is licensed under a Creative Commons Attribution 4.0 International License. Read Full License 


\section{Abstract}

Phenolic acids, as the predominant secondary metabolites of Salvia species, are largely used in pharmaceutical industries. The main aim of the study was to establish hairy root cultures of Salvia virgata Jacq. Also, the effects of methyl jasmonate (22.4 and $11.2 \mathrm{ppm}), \mathrm{Ag}^{+}$ions (5 and $2.5 \mathrm{ppm}$ ), and yeast extract (100 and 50 ppm) were assessed on total phenol, total flavonoid, rosmarinic acid, salvianolic acid A, and caffeic acid contents in the hairy roots after 1, 3 and 5 days of exposure. Results showed the used Agrobacterium rhizogenes strains (A4, ATCC15834, R1000, GM1534, and C58C1) differed in their ability to induce hairy roots on leaf explants. The transformed roots were molecularly confirmed using rolC gene and the highest transformation frequency ( $56 \%$ ) was obtained by ATCC 15834 strain. Among the established hairy root lines, the highest amount of rosmarinic acid $(0.45 \pm 0.01 \mathrm{mg} / \mathrm{g}$ DW) and dry root biomass $(2.29 \pm 0.04 \mathrm{~g})$ was obtained in AT3, the line which was induced by ATCC 15834 strain. The maximum accumulation of total phenol (123.6 $\pm 0.93 \mathrm{mg} \mathrm{GAE} / \mathrm{g} \mathrm{DW})$, total flavonoid (5.09 $\pm 0.07 \mathrm{mg}$ QUE$/ \mathrm{g}$ DW), rosmarinic acid $(18.45 \pm 0.8 \mathrm{mg} / \mathrm{g} \mathrm{DW})$, salvianolic acid $\mathrm{A}(2.11 \pm 0.04 \mathrm{mg} / \mathrm{g}$ DW) and caffeic acid $(2.61 \pm 0.02 \mathrm{mg} / \mathrm{g} \mathrm{DW})$ was observed in the hairy roots elicited with $22.4 \mathrm{ppm}$ methyl jasmonate on day three after treatment. The results support that elicitation could be an effective procedure for the improvement of caffeic acid derivatives production in S. virgata hairy root cultures.

\section{Introduction}

Salvia virgate Jacq., an annual plant belonging to the Lamiaceae family, is native to Asia (northeast of Iran) and southeastern Europe. The plant has traditionally been used for the treatment of skin diseases, wounds, and blood cancer (Baytop 1999; Poyraz and Koca 2006). Some of the important biological properties of this species, including antioxidant (Tepe 2008; karatoprak et al. 2016; Dehghani Latani et al. 2019), antimicrobial (Kursat et al. 2012; Alizadeh 2013; Golparvar et al. 2017), antifungal (Bayar and Yilar 2019), anti-inflammatory and antinociceptive activities (Akkol et al. 2008) have been reported in the literature.

Phenolic acids, including caffeic acid (CA), rosmarinic acid (RA), and salvianolic acid B (Sal-B) (also known as lithospermic acid B (LAB)), are principal polyphenolic compounds in Salvia species which exhibit multi-biological activities and health-benefit properties (Habtemariam 2018; Wang et al. 2019). Based on in vitro and in vivo studies, the presence of some phenolic acids such as CA, RA, Sal-A, and SalB, have been indicated in intact plant and shoot cultures of S. virgata (Tepe 2007; Kosar et al. 2008; Akkol et al. 2008; Ejtahed et al. 2015; Attaran Dowom et al. 2017; Fotovvat et al. 2018).

Recent studies have reported numerous biological/pharmacological properties for these phenolic acids, including antioxidant, antibacterial, antifungal (Weremczuk-Jeżyna et al. 2019; Grzegorczyk-Karolak et al. 2018; Katanić Stanković et al. 2020), antiviral (Ma et al. 2019; Kim et al. 2020), anti-inflammatory (Villalva et al. 2018; Liu et al. 2018), hypoglycemic (Huang et al. 2016; Jackson 2017; Salgueiro et al. 2018), and anticancer (Swamy et al. 2018; Zhang et al. 2018; Katary et al. 2019; Qin et al. 2019) activities. 
Furthermore, it has shown that RA and Sal-B could improve memory and cognitive impairment related to Alzheimer's disease (Shen et al. 2017; Gok et al. 2018).

Chemically, CA is the basic structural unit of phenolic acids in Salvia species. Rosmarinic acid is an ester of CA and 3, 4-dihydroxyphenyllactic acid, and Sal- B is identified as a dimmer of RA (Wang et al. 2019) (Fig. 1).

Biosynthesis of phenolic acids occurs mainly via the phenylpropanoid and tyrosine-derived pathways (Di et al. 2013). Many of the encoding genes for the critical enzymes in the biosynthetic pathways of phenolic acids, including phenylalanine ammonia-lyase ( $P A L)$, cinnamic acid 4-hydroxylase $(C 4 H)$, hydroxycinnamate coenzyme A ligase ( $4 C L$ ), tyrosine aminotransferase (TAT), 4-hydroxyphenylpyruvate reductase (HPPR), rosmarinic acid synthase (RAS), and a cytochrome P450-dependent monooxygenase (CYP98A14), were identified in S. miltiorrhiza (Di et al. 2013; Zhang et al. 2014; Wang et al. 2015; Xing et al. 2018b).

Due to the genetic stability, large biomass output, and high biosynthetic capacity, hairy root (HR) culture is considered as an alternative technique for secondary metabolite production, compared to native plant roots and cell/callus cultures (Hu and Du 2006; Ono and Tian 2011). Moreover, the application of HR cultures in many industrial and scientific fields, including designing of bioreactors, recombinant protein production, phytoremediation, and metabolic and genetic engineering, has been reported (Ashihara et al. 2011; Doran 2013; Kuma 2018).

It has demonstrated that the high amounts of phenolic acids, such as RA, are synthesized in the HR cultures of plants belonging to the Lamiaceae family including, Salvia officinalis L. (Grzegorczyk et al. 2006), S. miltiorrhiza Bunge (Yan et al. 2006; Zhao et al. 2011), Ocimum basilicum L. (Bais et al. 2002), Coleus forskohlii Briq. (Li et al. 2005), Nepeta cataria L. (Lee et al. 2010), as well as RA and LAB in S. miltiorrhiza (Xiao et al. 2010; Di et al. 2013).

Various elicitors including silver ions ( $\mathrm{Ag}^{+}$ions), yeast extract (YE) and methyl jasmonate (MeJA) can widely use to stimulate production and accumulation of secondary metabolites in HR cultures (Ge and Wu 2005; Pirian and Piri 2013; Ahmadi Moghadam et al. 2014). According to some reports, production of different phenolic acids, such as CA, RA, and Sal-B have been improved in HR cultures of $C$. blumei (Bauer et al. 2009), S. miltiorhiza (Yan et al. 2006; Xiao et al. 2009; Xiao et al. 2010; Xing et al. 2015; Xing et al. 2018b), S. officinalis (Grzegorczyk and Wysokińska 2009), and Mentha spicata L. (Yousefian et al. 2020) after the elicitation with $\mathrm{YE}, \mathrm{Ag}^{+}$ions and MeJA.

There is only one report (in Persian) available on the induction of HR cultures in S. virgata (Norouzi et al. 2017), and based on our knowledge, no report has been published regarding the elicitation of phenolic acids biosynthesis in HR cultures of $S$. virgata. Therefore, this study was designed to develop an efficient HR culture system for $S$. virgata, using different Agrobacterium rhizogenes strains, and to investigate the effects of biotic and abiotic elicitors on RA, CA, and Sal-A production in the transformed root cultures for the first time. 


\section{Materials And Methods \\ 2.1. Plant material}

Mature seeds of S. virgata were collected from wild-grown plants in August 2013 at Reine village (Bojnoord, North Khorasan province, Iran) located at latitude 57॰2区 N, 37॰23区 E longitude, and an elevation of $1765 \mathrm{~m}$ above sea level. The species was identified at the Ferdowsi University of Mashhad herbarium (FUMH), where a voucher specimen (No. 38128) of the plant was deposited. Seeds were surface sterilized with ethanol (70\%) for $1 \mathrm{~min}$, followed by sodium hypochlorite (5\%) for $5 \mathrm{~min}$, and rinsed three times with sterile distilled water. For germination, seeds were placed into glass jars containing $25 \mathrm{~mL}$ of Murashige and Skoog (MS) medium supplemented with sucrose (3\%) and agar (0.7 $\%)$. The $\mathrm{pH}$ of media was adjusted to $5.6-5.8$ before adding agar, and the MS basal medium was autoclaved at $120^{\circ} \mathrm{C}$ for $17 \mathrm{~min}$. The glass jars were kept in the dark for three days at $25 \pm 2{ }^{\circ} \mathrm{C}$, and after germination of the seeds, they were placed at $26 \pm 2{ }^{\circ} \mathrm{C}$ and $16 / 8 \mathrm{~h}$ (light/dark) photoperiod ( $45 \mathrm{M}$ photons $\mathrm{m}^{-2} \mathrm{~s}^{-1}$ provided by cool white fluorescent lamps) in a culture room. These conditions were also applied to all the experiments described below.

\subsection{Growth of Agrobacterium rhizogenes}

Five A. rhizogenes strains (ATCC15834, R1000, A4, C58C1 and GM1534), which were obtained from the Biotechnology Research Center, Karaj, Iran, were incubated on Luria-Bertani (LB) agar medium (Vervliet et al. 1975) with $50 \mathrm{ppm}$ rifampin at $28^{\circ} \mathrm{C}$ for $48 \mathrm{~h}$.

\subsection{Establishment of hairy root cultures}

Leaf explants were taken from S. virgata plants grown in vitro for 50 days. The explants were wounded with a needle dipped into $A$. rhizogenes cultures. Control explants were wounded with a sterile needle without bacteria. Infected and control explants were placed on hormone-free MS agar (0.7\%) medium and incubated in the dark at $25^{\circ} \mathrm{C}$. After two days of inoculation, the explants were transferred to MS basal medium supplemented with sucrose (3\%), cefotaxime (300 ppm), and Difco Bacto agar (0.7 \%) was used for solidifying medium. Root cultures were incubated under 16/8 h (light/dark) photoperiod (45 $\mathrm{M}$ photons $\mathrm{m}^{-2} \mathrm{~s}^{-1}$ provided by cool white fluorescent lamps) at $25^{\circ} \mathrm{C}$.

The experiment was repeated three times; 25 explants were used for each treatment $(n=25)$. The transformation frequencies (the percentages of explants forming roots after infection with $A$. rhizogenes strains) were determined 10-14 days after infection. From each strain, three obtained roots, longer than 1 $\mathrm{cm}$, were excised from explants and transferred individually into $250 \mathrm{~mL}$ Erlenmeyer flasks containing 50 $\mathrm{mL} 1 / 2 \mathrm{MS}$ liquid medium without growth regulators and supplemented with $300 \mathrm{mg} / \mathrm{L}$ cefotaxime to prevent bacterial spread. The cefotaxime concentration was gradually decreased to 200 and $100 \mathrm{mg} / \mathrm{L}$ during the second and third subcultures, respectively. The cultures were maintained on an incubator shaker at $100 \mathrm{rpm}$ at $25^{\circ} \mathrm{C}$ in the dark. After eight subcultures, when the antibiotic was eliminated from 
the medium, one fast-growth root line with the most RA content was obtained (ATCC15834 line AT3) and used for elicitors treatments.

\subsection{Confirmation of transgenic hairy root lines}

The genomic DNA (gDNA) from five putative transformed root lines of each strain and untransformed roots (negative control) was extracted from $100 \mathrm{mg}$ of plant tissue following the procedures described by Sharp et al. (1988) with slight modifications. In this study, DNA from A. rhizogenes ATCC15834 strain served as the positive control, and seedling roots were used as the negative control.

The PCR was performed to amplify an internal rolC gene fragment (612 bp). The PCR analysis was on the C1000 Touch TM 96-Well Thermal Cycler (Bio-Rad, USA) and began with $15 \mu \mathrm{L}$ reaction mixtures containing amplicon, gDNA (100 ng total DNA), and oligonucleotide primers in $10 \mu \mathrm{M}$ final concentration. The primers for detecting the rolC gene were 5'-ATG GCT GAA GAC GAC CTG TGT T-3' and 5'-TTA GCC GAT TGC AAA CTT GCA C-3'. The PCR program comprised of an initial denaturing step of 4 min at $95^{\circ} \mathrm{C}$ and 35 cycles, each consisting of $60 \mathrm{~s}$ at $95^{\circ} \mathrm{C}, 30 \mathrm{~s}$ at $55^{\circ} \mathrm{C}$ and $60 \mathrm{~s}$ at $72^{\circ} \mathrm{C}$, followed by a final extension step of $7 \mathrm{~min}$ at $72^{\circ} \mathrm{C}$. Approximately $10 \mu \mathrm{L}$ of the PCR products were electrophoresed on $1 \%$ (w/v) agarose gel, stained with GelRed, and visualized under UV on the Gel Imaging System (Bio-Doc, Germany). Predicted products of rolC were obtained apart from the control (non-induced root).

\subsection{Elicitor treatment}

Three elicitors, including $\mathrm{Ag}^{+}$ions, YE and MeJA, were tested at two concentrations. A stock solution of $\mathrm{Ag}^{+}$ions was prepared by dissolving $\mathrm{AgCl}$ in deionized water and added (2.5 and 5 ppm final concentrations) in liquid hormone-free 1/2 MS medium. Carbohydrate fraction of YE was made from commercial yeast extract (Cat. no.Y4250, Sigma) by ethanol precipitation as described by Hahn and Albersheim (1978) and added (50 and 100 ppm final concentration) in freshly prepared 1/2 MS liquid medium. A stock solution ( $0.1 \mathrm{M}$ ) of MeJA was prepared by dissolving it in 96 \% ethanol and added (11.2 and 22.4 ppm final concentrations) in autoclaved 1/2 MS liquid medium (Wang et al. 2015). All the elicitor solutions were sterilized by filtering through $0.2 \mu \mathrm{M}$ microfilters.

Hairy roots were cultured for 55 days (end of exponential growth phase), and then the old medium was substituted with $30 \mathrm{ml}$ of fresh 1/2 MS liquid medium supplemented with $\mathrm{Ag}^{+}$ions, MeJA and YE. Half strength MS liquid medium with the same volume of water or ethanol (instead of elicitors) was added to control cultures. Hairy roots were harvested 1, 3, and 5 days after elicitor treatments. All cultures were maintained at the same mentioned conditions (part 2-3).

\subsection{Extraction of phenolic compounds}

Harvested hairy roots were oven-dried at $40{ }^{\circ} \mathrm{C}$ to reach the constant dry weight and then grounded to a fine powder. Dried powders of plant materials were extracted with methanol (98 \%) (500 mg root material/10 mL solvent) by sonication for 30 minutes at room temperature. The extracts were then 
filtered using Whatman No.1 filter papers. After vacuum evaporation, the dried extracts were maintained at $-20^{\circ} \mathrm{C}$.

\subsection{Determination of total phenolic compounds}

The total phenolic (TP) content of the samples was determined by using Folin-Ciocalteu reagent and gallic acid as standard (Wojdylo et al. 2007). Briefly, $1 \mathrm{mg}$ of the dried extract sample was dissolved in 1 $\mathrm{mL}$ methanol (1000 ppm), then $100 \mu \mathrm{L}$ of the prepared solution was thoroughly mixed in a test tube with $2 \mathrm{~mL}$ water and $200 \mu \mathrm{L}$ Folin-Ciocalteu reagent for $3 \mathrm{~min}$, and the mixture was incubated with $1 \mathrm{~mL}$ of 20 $\%(\mathrm{w} / \mathrm{v})$ sodium carbonate solution at room temperature for $1 \mathrm{~h}$. The absorbance of the extracts was measured at $765 \mathrm{~nm}$ against a blank (a solution without the extract). A stock solution of gallic acid (800 ppm) was prepared in distilled water and diluted to appropriate concentrations (200-800 ppm) for the construction of a calibration curve. The concentration of TP in samples was measured using the calibration equation $\left(y=0.1427+0.0029 x, r^{2}=0.999\right)$ and expressed as $\mathrm{mg}$ of gallic acid equivalent (GAE) per g dry weight.

\subsection{Determination of total flavonoids}

Flavonoid concentration in the samples was measured spectrophotometrically, according to the procedure of Chang et al. (2002). The reaction mixture was prepared by mixing $0.5 \mathrm{~mL}$ of methanolic solution of dried extract (1000 ppm) with $1.5 \mathrm{~mL}$ methanol, $0.1 \mathrm{~mL} 10 \%(\mathrm{w} / \mathrm{v})$ aluminum chloride, $0.1 \mathrm{~mL}$ $1 \mathrm{M}$ potassium acetate and, $2.8 \mathrm{~mL}$ distilled water. After $30 \mathrm{~min}$ of incubation at room temperature, absorbance was measured at $415 \mathrm{~nm}$ against a blank without the extract. For the establishment of a calibration curve, different concentrations of quercetin (20-100 ppm) were prepared in distilled water using a stock solution (100 ppm). The total flavonoid (TF) content in samples was calculated by the standard curve equation $\left(y=-0.065+0.0088 x, r^{2}=0.939\right)$ and results were expressed as mg quercetin equivalent (QUE) per g dry weight.

\subsection{HPLC analysis of phenolic acids}

The content of phenolic acids was measured by the HPLC method. The HPLC apparatus was a Smartline model (Kenuer, Germany) with a quaternary pump and a reversed-phase column C18 Eurospher-100 (5 $\mu \mathrm{m}$ particles, $125 \mathrm{~mm} \times 4 \mathrm{~mm}$ ) coupled with a UV-VIS detector (D-14163 model). The data were processed by Software ChromGate (V 3.1). The separation was performed using a mobile phase consisted of water with $0.2 \%$ glacial acetic acid (solvent $A$ ) and acetonitrile (solvent $B$ ). The flow rate was kept at $1 \mathrm{~mL} / \mathrm{min}$. The initial condition was 90/10 (v/v) A/B and 75/25 (v/v) at $15 \mathrm{~min}$. The percentage of mobile-phase $A$ decreased to $20 \%$ at 40 min and reached $0 \%$ at $45 \mathrm{~min}$. This ratio remained stable until $50 \mathrm{~min}$, and in the next $5 \mathrm{~min}$, the percentage of mobile-phase $A$ increased linearly to $90 \%$. The injection volume was $20 \mu \mathrm{L}$, and peaks were monitored at $280 \mathrm{~nm}$. The samples were filtered through a hydrophilic PTFE membrane filter with a $0.45 \mu \mathrm{m}$ pore size before injection. Peaks were identified by congruent retention times compared with those of standards. Rosmarinic acid, Sal-A, and CA (Fig. 1) were detected and quantified using authentic standards obtained from Sigma. The content of each phenolic acid was calculated based on the equation, which was obtained from the corresponding 
standard calibration curve. The stock solutions of RA, Sal-A, and CA (400 ppm) were prepared in ethanol and diluted to appropriate concentration range for the construction of calibration curves. The concentrations of RA, Sal-A, and CA in samples were measured using calibration equations $\left(y_{\mathrm{RA}}=41606\right.$ $\left.x, r^{2}=0.996 ; y_{\text {Sal-A }}=19497 x, r^{2}=0.996 ; y_{C A}=7337.1 x, r^{2}=0.995\right)$. Each treatment was performed in three replicates.

\subsection{Statistical analysis}

All the tissue culture experiments were repeated at least three times in a completely randomized design. The data were subjected to one-way ANOVA using SPSS software version 16.0. Mean values were compared by Duncan's Multiple Range Test and reported as means \pm standard errors (SE). A probability of $P \leq 0.05$ was considered to be significant.

\section{Results}

\subsection{Establishment of $S$. virgata hairy root cultures and confirmation of transgenic status}

In this study, detached leaf explants from the in vitro 50-day-old plants were inoculated with five strains of $A$. rhizogenes. Hairy roots initials appeared on the incision sites of the explants within 10 days. After four weeks of the inoculation, all of the bacterial strains used in this study successfully induced hairy roots at the wounded sites of leaf explants. No root formation was observed in the control explants (Fig. 2). As shown in Fig. 3, all of the hairy roots, induced by five different strains, were confirmed to have rolC gene in their genomes.

According to the results, selected strains of $A$. rhizogenes showed a significant difference in their ability to induce HRs, and the infection frequency varied from $20.4 \pm 0.77$ to $56 \pm 2.67$ percent depending on the bacterial strain. The highest infection frequency (56\%) was found in the leaf explants infected with ATCC15834 strain, while the lowest infection frequency (20.4\%) was obtained in the explants inoculated with C58C1 strain (Fig. 4).

In the next step of the present study, three fast-growing hairy root lines were selected from all five groups of HR lines (induced by 5 different strains of $A$. rhizogenes), transferred to $1 / 2 \mathrm{MS}$ liquid medium, and then analyzed for their growth and RA content after 2 months. The highest dry weight and RA content were obtained in the HR line AT3, which was induced by ATCC15834 strain, so it was selected as the best line for elicitor treatments (Table 1). 
Table 1

Effects of different $A$. rhizogenes strains on dry weight and rosmarinic acid content in hairy root cultures of $S$. virgata after two months

\begin{tabular}{|llll|}
\hline Bacterial strain & Hairy root line & $\begin{array}{l}\text { Rosmarinic acid } \\
(\mathbf{m g} / \mathbf{g} \text { DW }\end{array}$ & $\begin{array}{l}\text { Dry Weight } \\
(\mathbf{g})\end{array}$ \\
\hline ATCC15834 & AT1 & $0.24 \pm 0.01^{\mathrm{e}-\mathrm{g}}$ & $1.23 \pm 0.06^{\mathrm{b}}$ \\
\hline ATCC15834 & AT2 & $0.22 \pm 0.01^{\mathrm{fg}}$ & $0.95 \pm 0.05^{\mathrm{d}}$ \\
\hline ATCC15834 & AT3 & $0.45 \pm 0.01^{\mathrm{a}}$ & $2.29 \pm 0.04^{\mathrm{a}}$ \\
\hline A4 & A1 & $0.27 \pm 0.03^{\mathrm{c}-\mathrm{e}}$ & $0.66 \pm 0.02^{\mathrm{g}}$ \\
\hline A4 & A2 & $0.27 \pm 0.01^{\mathrm{d}-\mathrm{g}}$ & $0.83 \pm 0.00^{\mathrm{e}}$ \\
\hline A4 & A3 & $0.32 \pm 0.02^{\mathrm{b}}$ & $1.13 \pm 0.06^{\mathrm{c}}$ \\
\hline R1000 & R1 & $0.32 \pm 0.01^{\mathrm{e}-\mathrm{g}}$ & $0.04 \pm 0.02^{\mathrm{j}}$ \\
\hline R1000 & R2 & $0.24 \pm 0.04^{\mathrm{e}-\mathrm{g}}$ & $0.72 \pm 0.02^{\mathrm{f}}$ \\
\hline R1000 & R3 & $0.32 \pm 0.01^{\mathrm{b}}$ & $0.08 \pm 0.03^{\mathrm{e}}$ \\
\hline C58C1 & C1 & $0.24 \pm 0.00^{\mathrm{e}-\mathrm{g}}$ & $0.11 \pm 0.00^{\mathrm{i}}$ \\
\hline C58C1 & C2 & $0.29 \pm 0.01^{\mathrm{b}-\mathrm{d}}$ & $0.20 \pm 0.00^{\mathrm{k}}$ \\
\hline C58C1 & C3 & $0.21 \pm 0.01^{\mathrm{g}}$ & $0.13 \pm 0.01^{\mathrm{i}}$ \\
\hline GM1534 & GM1 & $0.27 \pm 0.04^{\mathrm{c}-\mathrm{e}}$ & $0.04 \pm 0.04^{\mathrm{i}}$ \\
\hline GM1534 & GM2 & $0.26 \pm 0.02^{\mathrm{c}-\mathrm{f}}$ & $0.70 \pm 0.00 \mathrm{f}^{\mathrm{g}}$ \\
\hline GM1534 & GM3 & $0.30 \pm 0.03^{\mathrm{bc}}$ & $0.50 \pm 0.00^{\mathrm{h}}$ \\
\hline
\end{tabular}

Each value represents mean \pm SE of three replicates. Within a column, means followed by the same letter are not significantly different $(P \leq 0.05)$ according to Duncan's Multiple Range Test

\subsection{Effects of elicitors on total phenolic and flavonoid contents}

Total phenol and total flavonoid contents in the ATCC15834 strain-induced HRs (line AT3) were measured after 1 to 5 days of treatment with different concentrations of MeJA, YE, and $\mathrm{Ag}^{+}$ions. According to Table 2, MeJA-elicited HRs accumulated higher levels of TP and TF after 1, 3, and 5 days of elicitation, compared with control cultures. With the duration of MeJA exposure time, variations were detected in TP and TF contents of HRs, so the significant increases were observed on the 3rd day, followed by significant decreases on day 5 of elicitation. Based on the MeJA dosage and exposure time, the concentrations of 
TP and TF changed between $76.14 \pm 0.96$ to $123.66 \pm 0.93 \mathrm{mg} \mathrm{GAE} / \mathrm{g} \mathrm{DW}$ and $2.66 \pm 0.11$ to $5.09 \pm 0.07$ $\mathrm{mg}$ QUE/g DW, respectively. The highest accumulation of TP (2.06-fold of control) and TF (2.72-fold of control) was achieved with 22.4 ppm MeJA after three days of elicitation (Table 2).

As shown in Table 2, following $50 \mathrm{ppm}$ YE treatment, the content of TP on day 3 (90.39 $\pm 0.77 \mathrm{mg} \mathrm{GAE} / \mathrm{g}$ DW) and day 5 (88.63 $\pm 1.03 \mathrm{mg} \mathrm{GAE} / \mathrm{g} \mathrm{DW}$ ) of elicitation was significantly enhanced (1.98- and 1.61-fold of control, respectively). Application of $100 \mathrm{ppm}$ YE to HRs significantly elevated the amount of TP from $49.66 \pm 0.69 \mathrm{mg} \mathrm{GAE} / \mathrm{g}$ DW and $54.82 \pm 0.32 \mathrm{mg} \mathrm{GAE} / \mathrm{g}$ DW in control roots to $75.61 \pm 0.37 \mathrm{mg} \mathrm{GAE} / \mathrm{g}$ DW and $76.22 \pm 0.63 \mathrm{mg} \mathrm{GAE} / \mathrm{g}$ DW in the elicited HRs on day one and day five after elicitation, respectively. The increase in the exposure time of elicitation with $50 \mathrm{ppm}$ YE from one day to three days resulted in a significant increase in TP content, followed by a significant decrease on day 5 . However, in the presence of $100 \mathrm{ppm}$ YE, no significant change was found in TP content during the whole period of elicitation. The highest content of TP $(90.39 \pm 0.77 \mathrm{mg} \mathrm{GAE} / \mathrm{g}$ DW $)$ was observed in the cultures containing $50 \mathrm{ppm} \mathrm{YE}$, three days after elicitation (Table 2). The results represented that TF accumulation in HRs was significantly stimulated by both concentrations of YE. The yeast extract-treated HRs contained higher levels of TF on day 3 and 5, compared to the 1 st day after elicitation. The contents of TF varied from $2.13 \pm 0.02 \mathrm{mg}$ QUE/g DW (on day one after elicitation with 50 and $100 \mathrm{ppm}$ YE) to $3.20 \pm$ $0.3 \mathrm{mg}$ QUE/g DW (on day three after elicitation with $100 \mathrm{ppm} \mathrm{YE)} \mathrm{(Table} \mathrm{2).} \mathrm{Based} \mathrm{on} \mathrm{the} \mathrm{results}$ obtained from the treatment of $\mathrm{HRs}$ with $\mathrm{Ag}^{+}(2.5$ and $5 \mathrm{ppm})$, TP and TF contents were significantly enhanced with increasing exposure time from one day to five days (Table 2). However, no significant differences were observed between the TP content of HRs on day three and day five after treatment with $5 \mathrm{ppm}$ of $\mathrm{Ag}^{+}$ions. Generally, following the rise of the $\mathrm{Ag}^{+}$ion concentration in the culture medium from $2.5 \mathrm{ppm}$ to $5 \mathrm{ppm}$, no significant increase was observed in either TP or TF contents of HRs, except for day one where TP content showed 1.05-fold increase. The maximum contents of TP $(98.88 \pm 0.91)$ and TF (3.50 \pm 0.36$)$ were obtained in $\mathrm{HRs}$ treated with $2.5 \mathrm{ppm} \mathrm{Ag}^{+}$on the 5 th day after elicitation (1.80- and 1.88 -fold of control, respectively) (Table 2). 
Table 2

Effects of different concentrations of various elicitors on total phenol and total flavonoid contents in hairy roots (line AT3) of S. virgata

\begin{tabular}{|c|c|c|c|}
\hline $\begin{array}{l}\text { Elicitors } \\
\text { (ppm) }\end{array}$ & $\begin{array}{l}\text { Days after } \\
\text { treatment }\end{array}$ & $\begin{array}{l}\text { Total phenol content (mg } \\
\text { GAE/g DW) }\end{array}$ & $\begin{array}{l}\text { Total flavonoid content (mg } \\
\text { QUE/g DW) }\end{array}$ \\
\hline $\mathrm{Ag}^{+} 5$ & 1 & $77.31 \pm 0.12^{i}$ & $2.12 \pm 0.06^{\mathrm{hi}}$ \\
\hline $\mathrm{Ag}^{+} 5$ & 3 & $88.39 \pm 0.58^{e f}$ & $2.72 \pm 0.05^{f g}$ \\
\hline $\mathrm{Ag}^{+} 5$ & 5 & $89.80 \pm 0.9^{\mathrm{de}}$ & $3.15 \pm 0.04^{\text {de }}$ \\
\hline $\mathrm{Ag}^{+} 2.5$ & 1 & $73.41 \pm 0.79^{k}$ & $2.15 \pm 0.06^{h}$ \\
\hline $\mathrm{Ag}^{+} 2.5$ & 3 & $86.89 \pm 0.91^{f}$ & $2.94 \pm 0.04^{\mathrm{ef}}$ \\
\hline $\mathrm{Ag}^{+} 2.5$ & 5 & $98.88 \pm 0.91^{c}$ & $3.50 \pm 0.36^{c}$ \\
\hline YE 100 & 1 & $75.61 \pm 0.37^{j}$ & $2.13 \pm 0.02^{\mathrm{hi}}$ \\
\hline YE 100 & 3 & $77.14 \pm 2.42^{\mathrm{ij}}$ & $3.20 \pm 0.30^{d}$ \\
\hline YE 100 & 5 & $76.22 \pm 0.63^{i j}$ & $2.24 \pm 0.05^{\mathrm{h}}$ \\
\hline YE 50 & 1 & $41.55 \pm 0.70^{m}$ & $2.13 \pm 0.08^{h i}$ \\
\hline YE 50 & 3 & $90.39 \pm 0.77^{d}$ & $2.77 \pm 0.09^{f g}$ \\
\hline YE 50 & 5 & $88.63 \pm 1.03^{\mathrm{e}}$ & $2.66 \pm 0.08^{g}$ \\
\hline MeJA 22.4 & 1 & $76.14 \pm 0.96^{\mathrm{ij}}$ & $2.77 \pm 0.07^{f g}$ \\
\hline MeJA 22.4 & 3 & $123.66 \pm 0.93^{a}$ & $5.09 \pm 0.07^{a}$ \\
\hline MeJA 22.4 & 5 & $98.14 \pm 1.14^{c}$ & $4.28 \pm 0.08^{b}$ \\
\hline MeJA 11.2 & 1 & $80.02 \pm 0.27^{h}$ & $3.10 \pm 0.08^{\mathrm{de}}$ \\
\hline MeJA 11.2 & 3 & $103.05 \pm 1.05^{b}$ & $3.26 \pm 0.22^{d}$ \\
\hline MeJA 11.2 & 5 & $82.00 \pm 0.78^{g}$ & $2.66 \pm 0.11^{g}$ \\
\hline Control 1 & 1 & $49.66 \pm 0.69^{\circ}$ & $1.52 \pm 0.02^{k}$ \\
\hline Control 1 & 3 & $45.58 \pm 1.20^{i}$ & $1.75 \pm 0.10^{j}$ \\
\hline Control 1 & 5 & $54.82 \pm 0.32^{\circ}$ & $1.86 \pm 0.12^{j}$ \\
\hline Control 2 & 1 & $46.25 \pm 0.68^{n}$ & $1.85 \pm 0.07^{j}$ \\
\hline
\end{tabular}




\begin{tabular}{|llll|}
\hline $\begin{array}{l}\text { Elicitors } \\
(\mathbf{p p m})\end{array}$ & $\begin{array}{l}\text { Days after } \\
\text { treatment }\end{array}$ & $\begin{array}{l}\text { Total phenol content }(\mathrm{mg} \\
\text { GAE/g DW) }\end{array}$ & $\begin{array}{l}\text { Total flavonoid content }(\mathrm{mg} \\
\text { QUE/g DW) }\end{array}$ \\
\hline Control 2 & 3 & $59.92 \pm 0.91^{\circ}$ & $1.87 \pm 0.05^{\mathrm{j}}$ \\
\hline Control 2 & 5 & $45.65 \pm 0.77^{\mathrm{m}}$ & $1.91 \pm 0.11^{\mathrm{ij}}$ \\
\hline
\end{tabular}

Each value represents mean $\pm S E$ of three replicates. Within a column, means followed by the same letter are not significantly different $(P \leq 0.05)$ according to Duncan's Multiple Range Test. Hairy roots were sampled at 1, 3 and 5 days after the addition of selected elicitors. GAE, gallic acid equivalent; QUE, quercetin equivalent; $\mathrm{Ag}^{+}$ions, silver ions; $\mathrm{YE}$, yeast extract; MeJA, methyl jasmonate; Control 1, untreated roots; Control 2, ethanol-treated roots

\subsection{Effects of elicitors on phenolic acids content}

Hydromethanolic extracts of elicited and non-elicited HRs (line L3) were utilized for quantitative analysis of phenolic acids (RA, Sal-A and, CA) using the HPLC method. The HPLC chromatograms of phenolic acids from some treatment as compared to the control are shown in Fig. 5. The results obtained from HPLC analysis revealed that RA, CA and, Sal-A were present in three elicited and non-elicited HRs of $S$. virgata. Rosmarinic acid was the most abundant phenolic acid in the extracts, followed by CA and Sal-A. Salvianolic acid B was not detected in the HR samples (Fig. 5).

According to the results shown in Fig. 6, the levels of three studied phenolic acids in HRs treated with both concentrations (11.2 and $22.4 \mathrm{ppm}$ ) of MeJA were significantly elevated over three day period and then decreased on the 5th day after elicitation. The best stimulating effect of MeJA was achieved at the dose of $22.4 \mathrm{ppm}$, and the three analyzed phenolic acids tended to increase to a maximum level on day 3 post-elicitation. Hairy roots elicited with $22.4 \mathrm{ppm} \mathrm{MeJA}$ accumulated up to $18.45 \pm 0.8 \mathrm{mg} / \mathrm{g}$ DW RA, $2.61 \pm 0.02 \mathrm{mg} / \mathrm{g}$ DW CA, and $2.11 \pm 0.04 \mathrm{mg} / \mathrm{g}$ DW Sal-A over the 3-day, nearly 1.81-, 4.35- and 3.76-fold of untreated HRs on the same day (Fig. 6).

The data collected from YE-treated HRs, presented in Table 3 or Fig. 7, revealed that the increase in the contents of RA and Sal-A, which was observed during the first three days of elicitation with 50 and 100 ppm YE, was followed by a decrease on day five after treatment. The application of $50 \mathrm{ppm}$ YE for three days was the best treatment for the production of RA and Sal-A. Maximum amounts of RA (15.58 \pm 0.01 $\mathrm{mg} / \mathrm{g} \mathrm{DW})$ and Sal-A (1.65 $\pm 0.01 \mathrm{mg} / \mathrm{g} \mathrm{DW})$ were 1.44- and 2.42-fold of control, respectively (Fig. 6). Elicitation with YE at the concentration of $50 \mathrm{ppm}$ was more effective than $100 \mathrm{ppm}$ to accumulate CA in HRs. Caffeic acid accumulation in HRs treated with $50 \mathrm{ppm}$ YE significantly increased on days 3 and 5 of the elicitation period, as compared to day 1 . The highest accumulation of CA $(1.03 \pm 0.01 \mathrm{mg} / \mathrm{g} \mathrm{DW})$ was achieved on the 5th day of treatment (1.74-fold of control) (Fig. 6).

As shown in Fig. 6, during five days, elicitation with $\mathrm{Ag}^{+}$ions (2.5 and $5 \mathrm{ppm}$ ), in most cases, resulted in a

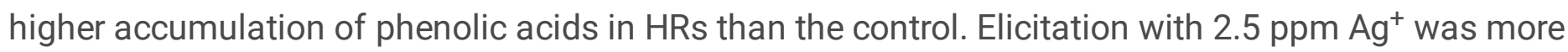

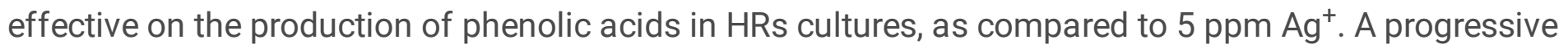


time-dependent enhancement in the contents of RA, Sal-A, and CA was found throughout elicitation with $2.5 \mathrm{ppm} \mathrm{Ag}{ }^{+}$. The highest production of RA $(16.01 \pm 0.09 \mathrm{mg} / \mathrm{g} \mathrm{DW}), \mathrm{CA}(1.99 \pm 0.01 \mathrm{mg} / \mathrm{g} \mathrm{DW})$, and Sal-A $(1.52 \pm 0.06 \mathrm{mg} / \mathrm{g} \mathrm{DW})$ were attained after a 5-day exposure of $\mathrm{HRs}$ to $2.5 \mathrm{ppm} \mathrm{Ag}{ }^{+}(1.54-, 2.45$ - and 3.37fold of control, respectively) (Fig. 6).

\section{Discussion}

This study aimed to establish HR cultures of $S$. virgata and, for the first time, to increase the production of phenolic acids based on the biotic and abiotic elicitor application. The findings revealed that all the tested strains of $A$. rhizogenes (ATCC15834, A4, R1000, C58C1, and GM1534) could generate HRs on the leaf segments. However, the infection frequency was significantly different among the five strains. The highest (56\%) and the lowest (20.4\%) frequencies of infection were obtained with ATCC15834 and C58C1 strains, respectively. Different $A$. rhizogenes strains have diverged in their abilities to induce HRs in plant species (Lee et al. 2010; Pirian et al. 2012; Shirazi et al. 2013; Setamam et al. 2014). Panda et al. (2017) reported that the optimum transformation efficiency (61\%) was attained in leaf explants of Semecarpus anacardium L. with ATCC15834 strain, in comparison with strains A4 and LBA 9402. Higher virulence of ATCC15834 strain (46\%) over other strains, A4 and SA79, (42\% and $21 \%$, respectively) of $A$. rhizogenes was also found in case of Boerhaavia diffusa L. leaf explants (Gupta et al. 2015). Similarly, a higher frequency of HR induction in explants infected with ATCC15834 strain than those infected with other strains has been reported in many different medicinal plants, including Althaea officinalis L. (Tavassoli and Afshar 2018), Perovskia abrotanoides Karel. (Ebrahimi et al. 2017), Helicteres isora L. (Kumar et al. 2014), Solenostemon scutellarioides L. (Saleh and Thuc 2009), Ipomoea batatas L. (Chandran and Potty 2008) and S. officinallis (Grzegorczyk et al. 2006). Different strains of A. rhizogenes display different transforming potentials, which can be attributed to their different plasmids (Giri and Narasu 2000; Pirian et al. 2012; Shirazi et al. 2013; Setamam et al. 2014; Tavassoli and Afshar 2018). Findings from the present study showed a more successful HR formation in $S$. virgata with the agropinetype (ATCC15834, R1000, and A4) than the mannopine-type (C58C1) strains of $A$. rhizogenesis. It has been proved that agropine-type strains, which have two T-DNA regions on their Ri plasmid $\left(T_{L}\right.$ and $\left.T_{R}\right)$, have more infection ability in comparison with mannopine-type strains (Hong et al. 2006; Verma et al. 2012). The genes encoding auxin have been localized on the $T_{R}$-DNA of the agropine-type Ri plasmid (Rawat et al. 2019). Therefore, agropine-types of $A$. rhizogenes strains are less dependent on endogenous auxin in explants, and this additional auxin source supports the HR formation (Saleh and Thuc 2009; Pal et al. 2013; Singh et al. 2018). Variation in phenotype, growth pattern and secondary metabolites production in HRs have been attributed to the diversity of Ri plasmids, T-DNA binding sites, and different numbers of T-DNA copies in different strains of A. rhizogenesis (Gupta et al. 2015; Thwe et al. 2016; Hassan and Belbasi 2017; Figlan and Makunga 2017). Moreover, the efficiency of different Agrobacterium strains for developing HRs is strongly dependent on plant species and must be determined empirically (Park et al. 2017; Thwe et al. 2016). 
In the present survey, among three distinct HR lines induced by ATCC15834 strain, line AT3 was the bestgrown line with maximum biomass production and highest RA accumulation. It has been revealed that different transformed root clones have various capacities for biomass accumulation and secondary metabolites biosynthesis (Grzegorczyk et al. 2006; Grzegorczyk-Karolak et al. 2018). The growth variations in HR clones might be originated from a different expression of T-DNA genes in individual root lines, which could adjust the biosynthesis of endogenous hormones or the susceptibility of plant cells to growth regulators (Ono and Tian 2011; Grzegorczyk-Karolak et al. 2018). Formation and growth of HRs are the consequences of excessive biosynthesis of endogenous auxins and cytokinins and enhanced sensitivity of transformed plant cells to these hormones, and ro/ genes appear to play a critical role in these processes (Hashem 2009). Gene rolA has a promoter region similar to those of some auxinregulated genes, and its product is probably a DNA binding protein and stimulator of growth (Matveeva et al. 2015). Primary studies proposed that $r o / B$ protein is a $\beta$-glucosidase releasing auxin (IAA) from its inactive conjugated forms, thus increasing auxin sensitivity (Esruch et al. 1991). Moreover, the rolB geneencoded product was shown to exhibit tyrosine phosphatase activity (Filippini 1996; Dilshad et al. 2015) and to interact with 14-3-3 proteins (Moriuchi et al. 2004; Matveeva et al. 2015), thus taking part in auxin signaling, enhancing the sensitivity of transformed cells toward auxin. It has been suggested that the product of rolC gene is a glucosidase liberating cytokinins from their bound forms (Estruch et al. 1991; Rangslang et al. 2018). Besides, the individual or combined rolgenes are recognized to be an efficient activator of secondary metabolites biosynthesis in plants (Sarkar et al. 2018). Products of these genes can activate the biosynthesis of different types of secondary metabolites in transgenic HRs, including alkaloids, anthraquinones, isoflavonoids, and ginsenosides (Bulgakov et al. 2013; Matveeva et al. 2015). Elicitation is a successful and probably the most widely applied approach for the induction of secondary metabolites biosynthesis in plant HR cultures (Halder et al. 2019). It has been reported that transformed root cultures can accumulate high levels of secondary metabolites typical of the mother plant or even new metabolites after elicitation with various biotic andabiotic elicitors (Naik et al. 2016a). Various factors, such as elicitor type and concentration, duration of elicitation, and age or stage of the culture at the time of elicitation, need to be optimized for the best production of target secondary metabolites (Naik et al. 2016b; Halder et al. 2019).

The current study revealed that the production of TP, TF, RA, CA, and Sal-A in the HR cultures of $S$. virgata is stimulated by biotic (YE) and abiotic ( $\mathrm{Ag}^{+}$ions and MeJA) elicitors. Similar studies have shown that $\mathrm{YE}$, MeJA, and $\mathrm{Ag}^{+}$ions significantly enhanced phenolic acids contents, especially RA, in HR cultures of $S$. miltiorrhiza (Yan et al. 2006; Zhang et al. 2014; Xing et al. 2015; Xing et al. 2018b), M. spicata (Yousefian et al. 2020) and $C$. forskohlii (Li et al. 2005). Differential effects of elicitors on the phenolic acid accumulation in HRs were observed in the present study. Although $\mathrm{YE}$ and $\mathrm{Ag}^{+}$ions had a stimulatory effect on the production of phenolic acids, the concentrations of these compounds were inversely proportional to the elicitor concentration. In contrast, MeJA had a positive dose-dependent impact on phenolic acids accumulation. Phenolic acid accumulation in HR cultures of C. blumei (Bauer et al. 2009) and S. miltiorrhiza (Chen et al. 2010) have been also related to the exogenous application of MeJA. The level of MeJA-induced phenolic acid accumulation in the present study was higher than those observed in 
the YE- and $\mathrm{Ag}^{+}$-elicited HRs. The optimal contents of TP, TF, RA, CA, and Sal-A in MeJA-elicited (at 22.4 ppm for three days) HRs of $S$. virgata were 2.06, 2.72, 1.81, 4.35 and, 3.76-fold of the control culture, respectively. Similarly, Li et al. (2005) indicated that compared with YE, MeJA (at $22.4 \mathrm{ppm}$ for seven days) was the most effective elicitor for the production of RA in $C$. forskohlii HR cultures, stimulating RA contents about 3.4 times greater than the control group. According to the report of Xiao et al. (2009), the application of MeJA, at $22.4 \mathrm{ppm}$ for six days, enhanced not only RA but also LAB accumulation in $S$. miltiorrhiza HR cultures by approximately 2- and 6.5-fold, respectively. Furthermore, the addition of 22.4 ppm MeJA improved the production of RA (on day 5) and Sal-B (on day 2) about 1.5-fold and 1.7-fold of the control in HR cultures of S. miltiorrhiza, respectively (Zhang et al. 2014). Xing et al. (2018b) also reported that RA and Sal-B concentrations reached their highest levels in S. miltiorrhiza HRs on days 3 and 6 after treatment with 22.4 ppm MeJA, respectively.

Based on the results of the current study, compared with the control cultures, accumulation of CA (4.35fold-increase) and Sal-A (3.76-fold-increase) in the transgenic roots treated with $22.4 \mathrm{ppm}$ MeJA was more affected than RA (1.81-fold-increase). However, RA was the major phenolic acid, accumulated in the roots compared with CA and Sal-A.

It is believed that MeJA, as a signaling molecule, stimulates the key enzymes taking part in the biosynthesis of secondary metabolites. During the MeJA-triggered signal transduction, several processes such as reactive oxygen species (ROS) production, calcium fluxes, protein phosphorylation, biosynthesis and activation of transcription factors, and expression of secondary metabolite biosynthetic genes have been reported by several researchers (Baenas et al. 2014; Giri et al. 2016; Ho et al. 2020). Recently, it has been revealed that methyl jasmonate-responsive transcription factors regulate RA and salvianolic acid biosynthesis (Yang et al. 2017). For instance, overexpression of SmMYC2, a basic helix-loop-helix transcription factor, and an activator of the jasmonate signaling pathway can induce the expression of target genes including PAL, TAT, and CYP98A14, as well as an increase in Sal-B accumulation in $S$. miltiorrhiza (Du et al. 2018). A jasmonate-responsive transcription factor (a novel AP2/ERF) has been reported to activate the expression of $R A S$ gene and positively regulates salvianolic acid biosynthesis in S. miltiorrhiza HRs (Sun et al. 2019). The results of a study by Deng et al. (2020) indicated that SmMYB2 activates the expression of cytochrome P450, thereby promoting MeJA-mediated biosynthesis of RA and Sal-B in S. miltiorrhiza HRs.

Yeast extract is the effective biotic elicitor widely used in plant cell and tissue cultures to increase secondary metabolism (Shi et al. 2007; Sørensen and Sondergaard 2014; Pastore et al. 2020). The stimulatory effect of YE on the production of secondary metabolites may be associated with the presence of various peptide and polysaccharide components in it such as chitin, $\mathrm{N}$-acetyl glucosamine oligomers, beta-glucans, glycopeptides, and ergosterol (Zhao et al. 2011; Eskandari et al. 2012; Baenas et al. 2014). Besides, the metal ions $\left(\mathrm{Ca}^{2+}, \mathrm{Co}, \mathrm{Zn}\right)$ contained in YE can probably act as abiotic elicitors, as proposed by Srivastava and Srivastava (2014), and Kochan et al. (2017). 
In the present study, significant enhancements in TP, RA, and Sal-A levels (1.98-, 1.44- and 2.42-fold of the control level, respectively) were found when YE (50 ppm) was applied to the $S$. virgata HR cultures for three days, and 1.74-fold-increase in the CA content was observed after five days. Similar to these results, a previous study reported that YE increased RA in HR cultures of S. miltiorrhiza (Zhao et al. 2011). According to the report of Chen et al. (2001), the accumulation of RA and LAB in S. miltiorrhiza HR

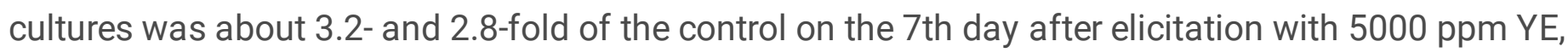
respectively. The highest accumulation of RA (1.9 times higher than the control) in HR cultures $C$. forskohlii was achieved at both concentrations of 100 and 10000 ppm YE, seven days after elicitation (Li et al. 2005). In the study of Yan et al. (2006) on HR cultures of S. miltiorrhiza, TP and RA contents

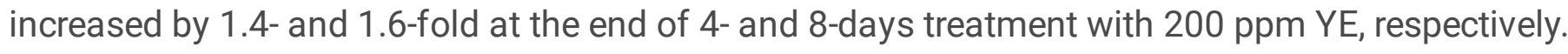
According to Bauer et al. (2009), RA contents in two YE-induced (5000 ppm YE for one day) HR clones of C. blumei were $20 \%$ and $44 \%$ higher than that obtained in the control group.

Yeast-derived elicitors can stimulate some of the key enzymes from the phenylpropanoid and tyrosinederived pathways (Yan et al. 2006; Zhai et al. 2016). Some reports showed YE improves RA biosynthetic pathway via the enhancement of PAL, TAT, and RAS activities (Sumaryono et al. 1991; Mizukami et al. 1992; Yan et al. 2006; Sahu et al. 2013). Based on a review by Zhai et al. (2016), it can be verified that various signal components such as ROS, $\mathrm{G}$ proteins, $\mathrm{Ca}^{2+}$ influx, jasmonate, and protein kinases are involved in the YE-induced production of secondary metabolites. Gene expression studies by Park et al. (2016) revealed a close relationship between the increased expression levels of phenylpropanoid biosynthetic pathway genes ( $P A L, C 4 H$, and $4 C L$ ) and RA accumulation in the YE-elicited cell cultures of Agastache rugosa. Although different families of transcription factors (WRKY, bHLHs, AP2-ERF, and MYBs) have been proposed as YE-responsive transcription factors which regulate the biosynthesis of some plant secondary metabolites (Yang et al. 2013; Gao et al. 2014; Zhou et al. 2017), it has not elucidated whether they are responsible for the YE-induced accumulation of phenolic acids.

Silver ions, as one of the most potent abiotic elicitor, is believed to stimulate the production of plants secondary metabolites (Naik and Al-Khayri 2016b). In the current study, after the addition of $2.5 \mathrm{ppm} \mathrm{Ag}^{+}$ (for five days), the accumulation of TP, TF, RA, CA, and Sal-A was estimated to be 1.8-, 1.88-, 1.54-, 2.45and 3.37-fold of the control, respectively. Similarly, as reported by Xing et al. (2015), the maximum concentrations of RA (1.3-fold of the control) and CA (about 1.4-fold of the control) in HRs of $S$. miltiorrhiza were determined after elicitation with $2.5 \mathrm{ppm} \mathrm{Ag}^{+}$ions (for six days). In another study involving S. miltiorrhiza HR cultures, TP and RA reached to the maximal levels (about 1.2- and 1.3-fold of the control, respectively) when HRs were treated with $2.5 \mathrm{ppm} \mathrm{Ag}{ }^{+}$ions for 4 and 8 days, respectively (Yan et al. 2006). Nevertheless, Xiao et al. (2010) reported that RA accumulation in HRs of S. miltiorrhiza was not affected by $\mathrm{Ag}^{+}$ions ( $2.5 \mathrm{ppm}$ ), while Sal-B (approx. 3.5 times higher than the control) dramatically responded to this elicitor.

$\mathrm{Ag}^{+}$-induced accumulation of different phenolic acids, including CA, RA, and LAB, in HRs of S. miltiorrhiza, were found to be coincident with the up-regulation of several genes (especially TAT, HPPR, and C4H) in 
tyrosine-derived and phenylpropanoid pathways (Xiao et al. 2010; Xing et al. 2015). It has been proposed that the ROS reaction cascade triggered by $\mathrm{Ag}^{+}$can activate the mitogen-activated protein kinases, thereby resulting in phosphorylation and activation of downstream transcription factors (Paeizi et al. 2018). Recent studies showed that certain members of WRKY transcription factors in Arabidopsis thaliana L. (Kohan-Baghkheirati and Geisler-Lee 2015) and bZIP transcription factors in S. miltiorrhiza (Zhang et al. 2018) are responsive to $\mathrm{Ag}^{+}$ions and regulate plant secondary metabolism in response to the abiotic stress. Based on some reports, $\mathrm{Ag}^{+}$-induced accumulation of secondary products can be related to the cross-talk with jasmonate signaling (Paeizi et al. 2018) and to the inhibition of ethylene signal transduction (Li et al. 2016; Khalili et al. 2010; Zhang and Wu 2003).

\section{Conclusion}

This study illustrated, for the first time, an efficient method for the production of phenolic acids in the well-established HR cultures of $S$. virgata using the elicitation technique. Among the five different strains of $A$. rhizogenes (ATCC15834, R1000, A4, C58C1, and GM1534), the ATCC15834 showed the highest capability to induce HR formation and RA production. The elicitation technique utilized here revealed the inducible nature of phenolic acids production in HRs of S. virgata. All tested elicitors ( $\mathrm{MeJA}, \mathrm{Ag}^{+}$, and $\mathrm{YE}$ ) positively influenced the contents of TP, TF, RA, CA, and Sal-A in HR cultures, and the highest accumulation of these phenolic components was achieved at $22.4 \mathrm{ppm}$ MeJA after three days.

Subsequent investigations relevant to elicitation and mechanism of phenolic acids biosynthesis need to be conducted to further utilize the potency of $S$. virgata HR cultures to produce more bioactive compounds.

\section{Abbreviations}

- HR: hairy root

- RA: rosmarinic acid

- CA: caffeic acid

- Sal-A: salvianolic acid A

- TP: total phenol

- TF: total flavonoid

- MeJA: methyl jasmonate

- YE: yeast extract

- $\mathrm{Ag}^{+}$ions: silver ions

- PCR: polymerase chain reaction

\section{Declarations}


This work was supported by a research grant funded by Ferdowsi University of Mashhad (no. 3/25607) for the plant physiology PhD thesis. The authors highly appreciate the Biotechnology Laboratory of Tehran University for HR cultures and the Plant Physiology Laboratory of Shahed University for HPLC analyses

\section{References}

1. Ahmadi Moghadam Y, Piri K, Bahramnejad B, Ghiasvand T (2014) Dopamine production in hairy root cultures of Portulaca oleracea (Purslane) using Agrobacterium rhizogenes. J Agric Sci Technol 16:409-420

2. Akkol EK, Göger F, Koşar M, Başer KHC (2008) Phenolic composition and biological activities of Salvia halophila and Salvia virgata from Turkey. Food Chem 108:942-949. https://doi.org/10.1016/j.foodchem.2007.11.071

3. Alizadeh A (2013) Essential oil constituents, antioxidant and antimicrobial activities of Salvia virgata Jacq. from Iran. J Essent Oil Bearing Plants 16:172-182. https://doi.org/10.1080/0972060X.2013.793974

4. Ashihara H, Crozier A, Komamine A (2011) Plant metabolism and biotechnology. Wiley, New York

5. Attaran Dowom S, Abrishamchi P, Radjabian T, Salami SA (2017) Enhanced phenolic acids production in regenerated shoot cultures of Salvia virgata Jacq. after elicitation with $\mathrm{Ag}^{+}$ions, methyl jasmonate and yeast extract. Ind Crops Prod 103:81-88. https://doi.org/10.1016/j.indcrop.2017.03.043

6. Baenas N, García-Viguera C, Moreno DA (2014) Elicitation: a tool for enriching the bioactive composition of foods. Molecules19:13541-13563. https://doi.org/10.3390/molecules190913541

7. Bais HP, Walker TS, Schweizer HP, Vivanco JM (2002) Root specific elicitation and antimicrobial activity of rosmarinic acid in hairy root cultures of Ocimum basilicum. Plant Physiol Biochem 40:983-995. https://doi.org/10.1016/S0981-9428(02)01460-2

8. Bauer N, Kiseljak D, Jelaska S (2009) The effect of yeast extract and methyl jasmonate on rosmarinic acid accumulation in Coleus blumei hairy roots. Biol Plant 53:650-656. https://doi.org/10.1007/s10535-009-0118-8

9. Bayar Y, Yilar M (2019) The antifungal and phytotoxic effect of different plant extracts of Salvia virgata Jacq. Fresenius Environ Bull 28:3492-3497

10. Baytop $T$ (1999) Therapy with medicinal plants in Turkey (past and present). Publ Istanbul Univ 312

11. Bulgakov VP, Shkryl YN, Veremeichik GN, Gorpenchenko TY, Vereshchagina YV (2013) Recent advances in the understanding of Agrobacterium rhizogenes-derived genes and their effects on stress resistance and plant metabolism. In: Doran P (ed) Biotechnology of hairy root systems. Springer, Berlin, pp 1-22

12. Chandran RP, Potty VP (2008) Induction of hairy roots through the mediation of four strains of Agrobacterium rhizogenes on five host plants. Indian J Biotechnol 7:122-128 
13. Chang CC, Yang MH, Wen HM, Chern JC (2002) Estimation of total flavonoid content in propolis by two complementary colorimetric methods. J Food Drug Anal 10:3

14. Chen H, Chena F, Chiu FC, Lo CM (2001) The effect of yeast elicitor on the growth and secondary metabolism of hairy root cultures of Salvia miltiorrhiza. Enzyme Microb Technol 28:100-105. https://doi.org/10.1016/S0141-0229(00)00284-2

15. Chen ZW, Zhang JJ, Zhao SJ, Wang ZT, Hu ZB (2010) Effect of methyl jasmonate on the accumulation of phenolic acids in Salvia miltiorrhiza hairy root. Chin Pharm J 45:970-974

16. Dehghani Latani M, Bidgoli RD, Akhbari M (2019) Salvia virgata L. Leaves Extract: qualitative and quantitative phenolic compounds and antioxidant activity. Arab J Med Aromat Plants 5:78-89. https://doi.org/10.48347/IMIST.PRSM/ajmap-v5i3.18668

17. Deng C, Wang Y, Huang F, Lu S, Zhao L, Ma X, Kai G (2020) SmMYB2 promotes salvianolic acid biosynthesis in the medicinal herb Salvia miltiorrhiza. J Integr Plant Biol 7:122-128. https://doi.org/10.1111/jipb.12943

18. Di P, Zhang L, Chen J, Tan H, Xiao Y, Dong X, Zhou X, Chen W $(2013){ }^{13} \mathrm{C}$ tracer reveals phenolic acids biosynthesis in hairy root cultures of Salvia miltiorrhiza. ACS Chem Biol 8:1537-1548. https://doi.org/10.1021/cb3006962

19. Dilshad E, Cusido RM, Palazon J, Estrada KR, Bonfill M, Mirza B (2015) Enhanced artemisinin yield by expression of rol genes in Artemisia annua. Malar J 14:1-10. https://doi.org/10.1186/s12936015-0951-5

20. Doran PM (2013) Biotechnology of hairy root systems. Springer, Berlin

21. Du T, Niu J, Su J, Li S, Guo X, Li L, Cao X, Kang J (2018) SmbHLH37 functions antagonistically with SmMYC2 in regulating jasmonate-mediated biosynthesis of phenolic acids in Salvia miltiorrhiza. Front Plant Sci 9:1720. https://doi.org/10.3389/fpls.2018.01720

22. Ebrahimi S, Zaker A, Abrishamchi P, Bahrami AR, Ganjeali A, Sodagar N (2017) Hairy root induction and secondary metabolite production in Perovskia abrotanoides Karel. J Plant Process Function 6:17-26

23. Ejtahed RS, Radjabian T, Tafreshi SAH (2015) Expression analysis of phenylalanine ammonia lyase gene and rosmarinic acid production in Salvia officinalis and Salvia virgata shoots under salicylic acid elicitation. Appl Biochem Biotechnol 176:1846-1858. https://doi.org/10.1007/s12010-0151682-3

24. Eskandari SA, Piri K, Kayhanfar M, Hasanloo T (2012) Influence of jasmonic acids, yeast extract and salicylic acid on growth and accumulation of hyosciamine and scopolamine in hairy root cultures of Atropa belladonna L. Int J Agric Res Rev 2:403-409

25. Estruch JJ, Parets-Soler A, Schmülling T, Spena A (1991) Cytosolic localization in transgenic plants of the rolC peptide from Agrobacterium rhizogenes. Plant Mol Biol 17:547-550

26. Figlan S, Makunga NP (2017) Genetic transformation of the medicinal plant Salvia runcinata L. f. using Agrobacterium rhizogenes. S Afr J Bot 112:193-202. https://doi.org/10.1016/j.sajb.2017.05.029 
27. Filippini F, Rossi V, Marin O, Trovato M, Costantino P, Downey PM, Schiavo FL, Terzi M (1996) A plant oncogene as a phosphatase. Nature 379:499-500

28. Fotovvat M, Radjabian T, Saboora A (2018) HPLC fingerprint of important phenolic compounds in some Salvia L. species from Iran. Rec Nat Prod 13:37-49.

https://doi.org/10.25135/rnp.72.18.02.228

29. Gao W, Sun HX, Xiao H, Cui G, Hillwig ML, Jackson A, Wang X, Shen Y, Zhao N, Zhang L, Wang XJ (2014) Combining metabolomics and transcriptomics to characterize tanshinone biosynthesis in Salvia miltiorrhiza. BMC Genom 15:73. https://doi.org/10.1186/1471-2164-15-73

30. Ge X, Wu J (2005) Tanshinone production and isoprenoid pathways in Salvia miltiorrhiza hairy roots induced by $\mathrm{Ag}^{+}$and yeast elicitor. Plant Sci 168:487-491.

https://doi.org/10.1016/j.plantsci.2004.09.012

31. Giri A, Narasu ML (2000) Transgenic hairy roots: recent trends and applications. Biotechnol Adv 18:1-22. https://doi.org/10.1016/S0734-9750(99)00016-6

32. Giri CC, Zaheer M (2016) Chemical elicitors versus secondary metabolite production in vitro using plant cell, tissue and organ cultures: recent trends and a sky eye view appraisal. Plant Cell Tissue Organ Cult 126:1-18. https://doi.org/10.1007/s11240-016-0985-6

33. Gok DK, Hidisoglu E, Ocak GA, Er H, Acun AD, Yargıcoglu P (2018) Protective role of rosmarinic acid on amyloid beta 42-induced echoic memory decline: implication of oxidative stress and cholinergic impairment. Neurochem Int 118:1-13. https://doi.org/10.1016/j.neuint.2018.04.008

34. Golparvar AR, Hadipanah A, Gheisari MM, Naderi D, Rahmaniyan S, Khorrami M (2017) Chemical composition and antimicrobial activity of essential oil of Salvia officinalis L. and Salvia virgata Jacq. J Herb Drugs 8:71-78. https://doi 10.18869/JHD.2017.71

35. Grzegorczyk I, Królicka A, Wysokińska H (2006) Establishment of Salvia officinalis L. hairy root cultures for the production of rosmarinic acid. Z Naturforsch C J Biosci 61:351-356. https://doi.org/10.1515/znc-2006-5-609

36. Grzegorczyk I, Wysokińska H (2009) The effect of methyl jasmonate on production of antioxidant compounds in shoot cultures of Salvia officinalis L. Herba Pol 55:238-243

37. Grzegorczyk-Karolak I, Kuźma Ł, Lisiecki P, Kiss A (2018) Accumulation of phenolic compounds in different in vitro cultures of Salvia viridis $\mathrm{L}$. and their antioxidant and antimicrobial potential. Phytochem Lett 30:324-332. https://doi.org/10.1016/j.phytol.2019.02.016

38. Gupta R, Pandey P, Singh S, Singh DK, Saxena A, Luqman S, Bawankule DU, Banerjee S (2015) Advances in Boerhaavia diffusa hairy root technology: a valuable pursuit for identifying strain sensitivity and up-scaling factors to refine metabolite yield and bioactivity potentials. Protoplasma 253:1145-1158. https://doi.org/10.1007/s00709-015-0875-5

39. Habtemariam S (2018) Molecular pharmacology of rosmarinic and salvianolic acids: Potential seeds for alzheimer's and vascular dementia drugs. Int J Mol Sci 19:458. https://doi.org/10.3390/ijms19020458 
40. Hahn MG, Albersheim P (1978) Host-pathogen interactions: XIV. Isolation and partial characterization of an elicitor from yeast extract. Plant Physiol 62:107-111. https://doi.org/10.1104/pp.62.1.107

41. Halder M, Sarkar S, Jha S (2019) Elicitation: A biotechnological tool for enhanced production of secondary metabolites in hairy root cultures. Eng Life Sci 19:880-895. https://doi.org/10.1002/elsc.201900058

42. Hashem EA (2009) Estimation of the endogenous auxins and cytokinins in hairy roots incited on Solanum dulcamara plants by Ri plasmid of Agrobacterium rhizogenes. Aust J Basic Appl Sci 3:142-147

43. Hassan SA, Belbasi Z (2017) Improvemnet of hairy root induction in Artemisia annua by various strains of Agrobacterium rhizogenes. Banat's J Biotechnol 8:25. https://doi.org/10.7904/20684738-VIII(15)-25

44. Ho TT, Murthy HN, Park SY (2020) Methyl jasmonate induced oxidative stress and accumulation of secondary metabolites in plant cell and organ cultures. Int J Mol Sci 21:716. https://doi.org/10.3390/ijms21030716

45. Hong SB, Peebles CA, Shanks JV, San KY, Gibson SI (2006) Terpenoid indole alkaloid production by Catharanthus roseus hairy roots induced by Agrobacterium tumefaciens harboring rol ABC genes. Biotechnol Bioeng 93:386-390. https://doi.org/10.1002/bit.20699

46. Hu ZB, Du M (2006) Hairy root and its application in plant genetic engineering. J Integr Plant Biol 48:121-127. https://doi.org/10.1111/j.1744-7909.2006.00121

47. Huang MQ, Zhou CJ, Zhang YP, Zhang XQ, Xu W, Lin J, Wang PJ (2016) Salvianolic acid B ameliorates hyperglycemia and dyslipidemia in $\mathrm{db} / \mathrm{db}$ mice through the AMPK pathway. Cell Physiol Biochem 40:933-943. https://doi.org/10.1159/000453151

48. Jackson KMP (2017) Anti-diabetic effects of bitter botanicals. Dissertation, North Carolina State University

49. Karatoprak G, Ilgün S, Koşar M (2016) Antioxidant properties and phenolic composition of Salvia virgata Jacq. Turk J Pharm Sci 13:201-212. https://doi.org/10.1055/s-0031-1282693

50. Katanić Stanković JS, Srećković N, Mišić D, Gašić U, Imbimbo P, Monti DM, Mihailović V (2020) Bioactivity, biocompatibility and phytochemical assessment of lilac sage, Salvia verticillata L. (Lamiaceae)-A plant rich in rosmarinic acid. Ind Crops Prod 143:111932. https://doi.org/10.1016/j.indcrop.2019.111932

51. Katary MA, Abdelsayed R, Alhashim A, Abdelhasib M, Elmarakby AA (2019) Salvianolic acid b slows the progression of breast cancer cell growth via enhancement of apoptosis and reduction of oxidative stress, inflammation, and angiogenesis. Int J Mol Sci 20:5653. https://doi.org/10.3390/ijms20225653

52. Khalili M, Hasanloo T, Kazemi Tabar SK (2010) $\mathrm{Ag}^{+}$enhanced silymarin production in hairy root cultures of 'Silybum Marianum' (L.) Gaertn. Plant Omics 3:109

53. Kim SH, Lee J, Jung YL, Hong A, Nam SJ, Lim BK (2020) Salvianolic acid B inhibits hand-foot-mouth disease enterovirus 71 replication through enhancement of AKT signaling pathway. J Microbiol 
Biotechnol 30:38-43. https://doi.org/10.4014/jmb.1907-07079

54. Kochan E, Szymczyk P, Kuźma Ł, Lipert A, Szymańska G (2017) Yeast extract stimulates ginsenoside production in hairy root cultures of American ginseng cultivated in shake flasks and nutrient sprinkle bioreactors. Molecules 22:880. https://doi.org/10.3390/molecules22060880

55. Kohan-Baghkheirati E, Geisler-Lee J (2015) Gene expression, protein function and pathways of Arabidopsis thaliana responding to silver nanoparticles in comparison to silver ions, cold, salt, drought, and heat. Nanomater 5:436-467. https://doi.org/10.3390/nano5020436

56. Koşar M, Göger F, Can Başer KH (2008) In vitro antioxidant properties and phenolic composition of Salvia virgata Jacq. from Turkey. J Agric Food Chem 56:2369-2374. https://doi.org/10.1021/jf073516b

57. Kumar N, Singh AK (2014) Plant profile, phytochemistry and pharmacology of Avartani (Helicteres isora Linn.): A review. Asian Pac J Trop Biomed 4:S22-S26. https://doi.org/10.12980/APJTB.4.2014C872

58. Kumar N (2018) Biotechnological approaches for medicinal and aromatic plants: Conservation, genetic improvement and utilization. Springer, Singapore

59. Kursat M, Erecevit P, Sari A, Emre I, Kirbağ S (2012) The antimicrobial activities of seed fatty acid extracts from some Salvia L. species. Turk J Sci Technol 7:31-36

60. Lee SY, Kim SG, Song WS, Kim YK, Park N, Park SU (2010) Influence of different strains of Agrobacterium rhizogenes on hairy root induction and production of alizarin and purpurin in Rubia akane Nakai. Rom Biotechnol Lett 15:5405-5409

61. Li B, Wang B, Li H, Peng L, Ru M, Liang Z, Yan X, Zhu Y (2016) Establishment of Salvia castanea Diels $\mathrm{f}$. tomentosa Stib. hairy root cultures and the promotion of tanshinone accumulation and gene expression with $\mathrm{Ag}^{+}$, methyl jasmonate, and yeast extract elicitation. Protoplasma 253:87-100. https://doi.org/10.1007/s00709-015-0790-9

62. Li W, Koike K, Asada Y, Yoshikawa T, Nikaido T (2005) Rosmarinic acid production by Coleus forskohlii hairy root cultures. Plant Cell Tissue Organ Cult 80:151-155. https://doi.org/10.1007/s11240-004-9541-x

63. Liu H, Ma S, Xia H, Lou H, Zhu F, Sun L (2018) Anti-inflammatory activities and potential mechanisms of phenolic acids isolated from Salvia miltiorrhiza f. alba roots in THP-1 macrophages. J Ethnopharmacol 222:201-207. https://doi.org/10.1016/j.jep.2018.05.008

64. Ma Y, Cong W, Huang H, Sun L, Mai AH, Boonen K, Maryam W, De Borggraeve W, Luo G, Liu Q, Schoofs $L$ (2019) Identification of fukinolic acid from Cimicifuga heracleifolia and its derivatives as novel antiviral compounds against enterovirus A71 infection. Int J Antimicrob Agents 53:128-136. https://doi.org/10.1016/j.ijantimicag.2018.07.014

65. Matveeva TV, Sokornova SV, Lutova LA (2015) Influence of Agrobacterium oncogenes on secondary metabolism of plants. Phytochem Rev 14:541-554. https://doi.org/10.1007/s11101-015-9409-1

66. Mizukami H, Ogawa T, Ohashi H, Ellis BE (1992) Induction of rosmarinic acid biosynthesis in Lithospermum erythrorhizon cell suspension cultures by yeast extract. Plant Cell Rep 11:480-483. 
https://doi.org/10.1007/BF00232695

67. Moriuchi H, Okamoto C, Nishihama R, Yamashita I, Machida Y, Tanaka N (2004) Nuclear localization and interaction of ro/ $\mathrm{B}$ with plant 14-3-3 proteins correlates with induction of adventitious roots by the oncogene ro/B. The Plant J 38:260-275. https://doi.org/10.1111/j.1365-313X.2004.02041.X

68. Naik PM, Al-Khayri JM (2016a) Abiotic and biotic elicitors-role in secondary metabolites production through in vitro culture of medicinal plants. In: Shanker AK, Shanker C (eds) Abiotic and biotic stress in plants: recent advances and future perspectives, 1 stedn. Intech Open, London, pp 247-277. http://dx.doi.org/10.5772/61442

69. Naik PM, Al-Khayri JM (2016b) Impact of abiotic elicitors on in vitro production of plant secondary metabolites: a review. J Adv Res Biotech 1:7. http://dx.doi.org/10.15226/2475-4714/1/2/00102

70. Norouzi R, Babalar M, Mirmasoumi M (2017) Investigation of hairy root induction in some Salvia L. species. Nova Biologica Reperta 4:173-180

71. Ono NN, Tian L (2011) The multiplicity of hairy root cultures: prolific possibilities. Plant Sci 180:439446. https://doi.org/10.1016/j.plantsci.2010.11.012

72. Paeizi M, Karimi F, Razavi K (2018) Changes in medicinal alkaloids production and expression of related regulatory and biosynthetic genes in response to silver nitrate combined with methyl jasmonate in Catharanthus roseus in vitro propagated shoots. Plant Physiol Biochem 132:623-632. https://doi.org/10.1016/j.plaphy.2018.10.015

73. Pal A, Swain SS, Mukherjee AK, Chand PK (2013) Agrobacterium pRi TL-DNA ro/B and TR-DNA opine genes transferred to the spiny amaranth (Amaranthus spinosus L.), a nutraceutical crop. Food Technol Biotechnol 51:26-35

74. Panda BM, Mehta UJ, Hazra S (2017) Optimizing culture conditions for establishment of hairy root culture of Semecarpus anacardium L. 3 Biotech 7:21. https://doi.org/10.1007/s13205-017-0608-x

75. Park CH, Zhao S, Yeo HJ, Park YE, Baska TB, Arasu MV, Al-Dhabi NA, Park SU (2017) Comparison of different strains of Agrobacterium rhizogenes for hairy root induction and betulin and betulinic acid production in Morus alba. Nat Prod Commun 12:479-482.

https://doi.org/10.1177/1934578X1701200403

76. Park WT, Arasu MV, Al-Dhabi NA, Yeo SK, Jeon J, Park JS, Lee SY, Park SU (2016) Yeast extract and silver nitrate induce the expression of phenylpropanoid biosynthetic genes and induce the accumulation of rosmarinic acid in Agastache rugose cell culture. Molecules 21:426. https://doi.org/10.3390/molecules21040426

77. Pastore C, Allegro G, Valentini G, Pizziolo A, Battista F, Spinelli F, Filippetti I (2020) Foliar application of specific yeast derivative enhances anthocyanins accumulation and gene expression in Sangiovese cv (Vitis vinifera L.). Sci Rep 10:1-10. https://doi.org/10.1038/s41598-020-68479-0

78. Pirian K, Piri K (2013) Influence of yeast extract as a biotic elicitor on noradrenaline production in hairy root culture of Portulaca oleracea L. Int J Agron Plant Prod 4:2960-2964

79. Pirian K, Piri K, Ghiyasvand T (2012) Hairy roots induction from Portulaca oleracea using Agrobacterium rhizogenes to noradrenaline's production. Intl Res J Appl Basic Sci 3:642-649 
80. Poyraz IE, Koca F (2006) Morphological investigations on some medicinal Salvia L. Species in Eskişehir. Anadolu Univ J Sci Technol 7:443-450

81. Qin F, Yao L, Lu C, Li C, Zhou Y, Su C, Chen B, Shen Y (2019) Phenolic composition, antioxidant and antibacterial properties, and in vitro anti-HepG2 cell activities of wild apricot (Armeniaca Sibirica L. Lam) kernel skins. Food Chem Toxicol 129:354-364. https://doi.org/10.1016/j.fct.2019.05.007

82. Rangslang RK, Liu Z, Lütken H, Favero BT (2018) Agrobacterium spp. genes and ORFs: Mechanisms and applications in plant science. Cienc Agrotecnol 42:453-463. https://doi.org/10.1590/141370542018425000118

83. Rawat JM, Bhandari A, Raturi M, Rawat B (2019) Agrobacterium rhizogenes mediated hairy root cultures: a promising approach for production of useful metabolites. In: Gupta VG, Pandey A (eds) New and future developments in microbial biotechnology and bioengineering, 1st edn. Elsivior, USA, pp 103-118

84. Sahu R, Gangopadhyay M, Dewanjee S (2013) Elicitor-induced rosmarinic acid accumulation and secondary metabolism enzyme activities in Solenostemon scutellarioides. Acta Physiol Plant 35:1473-1481. https://doi.org/10.1007/s11738-012-1188-3

85. Saleh MN, Thuc JV (2009) Assessment of hairy roots induction in Solenostemon scutellarioides leaves by different strains of Agrobacterium rhizogenes. Afr J Biotechnol 8:3519-3523

86. Salgueiro AC, Folmer V, Bassante FE, Cardoso MH, da Rosa HS, Puntel GO (2018) Predictive antidiabetic activities of plants used by persons with Diabetes mellitus. Complement Ther Med 41:19. https://doi.org/10.1016/j.ctim.2018.08.009

87. Sarkar S, Ghosh I, Roychowdhury D, Jha S (2018) The effects of rol genes of Agrobacterium rhizogenes on morphogenesis and secondary metabolite accumulation in medicinal plants. In: Kumar N (ed) Biotechnological approaches for medicinal and aromatic plants. Springer, Singapore, pp 27-51

88. Setamam NM, Sidik NJ, Rahman ZA, Zain CRCM (2014) Induction of hairy roots by various strains of Agrobacterium rhizogenes in different types of Capsicum species explants. BMC Res Notes 7:1-8. https://doi.org/10.1186/1756-0500-7-414

89. Sharp PJ, Kreis M, Shewry PR, Gale MD (1988) Location of $\beta$-amylase sequences in wheat and its relatives. Theor Appl Genet 75:286-290

90. She L, Han B, Geng Y, Wang J, Wang Z, Wang M (2017) Amelioration of cognitive impairments in APPswe/PS1dE9 mice is associated with metabolites alteration induced by total salvianolic acid. PLoS One 12:e0174763. https://doi.org/10.1371/journal.pone.0174763

91. Shi M, Kwok KW, Wu JY (2007) Enhancement of tanshinone production in Salvia miltiorrhiza Bunge (red or Chinese sage) hairy-root culture by hyperosmotic stress and yeast elicitor. Biotechnol Appl Biochem 46:191-196. https://doi.org/10.1042/BA20060147

92. Shirazi Z, Piri K, Asl AM, Hasanloo T (2013) Establishment of Inula helenium hairy root culture with the use of Agrobacterium rhizogenes. Int Res J Appl Basic Sci 4:1034-1038 
93. Singh RS, Chattopadhyay T, Thakur D, Kumar N, Kumar T, Singh PK (2018) Hairy root culture for in vitro production of secondary metabolites: a promising biotechnological approach. In: Kumar N (ed) Biotechnological approaches for medicinal and aromatic plants. Springer, Singapore, pp 235-250

94. Sørensen JL, Sondergaard TE (2014) The effects of different yeast extracts on secondary metabolite production in Fusarium. Int J Food Microbiol 170:55-60.

https://doi.org/10.1016/j.jijoodmicro.2013.10.024

95. Srivastava S, Srivastava AK (2014) Effect of elicitors and precursors on azadirachtin production in hairy root culture of Azadirachta indica. Appl Biochem Biotechnol 172:2286-2297. https://doi.org/10.1007/s12010-013-0664-6

96. Sumaryono W, Proksch P, Hartmann T, Nimtz M, Wray V (1991) Induction of rosmarinic acid accumulation in cell suspension cultures of Orthosiphon aristatus after treatment with yeast extract. Phytochemistry 30:3267-3271. https://doi.org/10.1016/0031-9422(91)83190-V

97. Sun M, Shi M, Wang Y, Huang Q, Yuan T, Wang Q, Wang C, Zhou W, Kai G (2019) The biosynthesis of phenolic acids is positively regulated by the JA-responsive transcription factor ERF115 in Salvia miltiorrhiza. J Exp Bot 70:243-254. https://doi.org/10.1093/jxb/ery349

98. Swamy MK, Sinniah UR, Ghasemzadeh A (2018) Anticancer potential of rosmarinic acid and its improved production through biotechnological interventions and functional genomics. Appl Microbiol Biotechnol 102:7775-7793. https://doi.org/10.1007/s00253-018-9223-y

99. Tavassoli P, Afshar AS (2018) Influence of different Agrobacterium rhizogenes strains on hairy root induction and analysis of phenolic and flavonoid compounds in marshmallow (Althaea officinalis L.). 3Biotech 8:351. https://doi.org/10.1007/s13205-018-1375-z

100. Tepe B, Eminagaoglu O, Akpulat HA, Aydin E (2007) Antioxidant potentials and rosmarinic acid levels of the methanolic extracts of Salvia verticillata (L.) subsp. verticillata and S. verticillata (L.) subsp. amasiaca (Freyn \& Bornm.) Bornm. Food Chem 100:985-989. https://doi.org/10.1016/j.biortech.2007.04.008

101. Thwe A, Valan Arasu M, Li X, Park CH, Kim SJ, Al-Dhabi NA, Park SU (2016) Effect of different Agrobacterium rhizogenes strains on hairy root induction and phenylpropanoid biosynthesis in tartary buckwheat (Fagopyrum tataricum Gaertn). Front Microbiol 7:318. https://doi.org/10.3389/fmicb.2016.00318 0

102. Verma P, Mathur AK, Shanker K (2012) Growth, alkaloid production, rol genes integration, bioreactor up-scaling and plant regeneration studies in hairy root lines of Catharanthus roseus. Plant Biosyst 146:27-40. https://doi.org/10.1080/11263504.2011.649797

103. Vervliet G, Holsters M, Teuchy H, Van Montagu M, Schell J (1975) Characterization of different plaque-forming and defective temperate phages in Agrobacterium strains. J Gen Virol 26:33-48. https://doi.org/10.1099/0022-1317-26-1-33

104. Villalva M, Jaime L, Aguado E, Nieto JA, Reglero G, Santoyo S (2018) Anti-inflammatory and antioxidant activities from the basolateral fraction of Caco-2 cells exposed to a rosmarinic acid enriched extract. J Agric Food Chem 66:1167-1174. https://doi.org/10.1021/acs.jafc.7b06008 
105. Wang J, Qian J, Yao L, Lu Y (2015) Enhanced production of flavonoids by methyl jasmonate elicitation in cell suspension culture of Hypericum perforatum. Bioresour Bioprocess 2:5. https://doi.org/10.1186/s40643-014-0033-5

106. Wang J, Xu J, Gong X, Yang M, Zhang C, Li M (2019) Biosynthesis, chemistry, and pharmacology of polyphenols from Chinese Salvia species: A review. Molecules 24:155. https://doi.org/10.3390/molecules24010155

107. Weremczuk-Jeżyna I, Kochan E, Szymczyk P, Lisiecki P, Kuźma Ł, Grzegorczyk-Karolak I (2019) The antioxidant and antimicrobial properties of phenol-rich extracts of Dracocephalum forrestii WW Smith shoot cultures grown in the nutrient sprinkle bioreactor. Phytochem Lett 30:254-260. https://doi.org/10.1016/j.phytol.2019.01.032

108. Wojdyło A, Oszmiański J, Czemerys R (2007) Antioxidant activity and phenolic compounds in 32 selected herbs. Food Chem 105:940-949. https://doi.org/10.1016/j.foodchem.2007.04.038

109. Xiao Y, Gao S, Di P, Chen J, Chen W, Zhang L (2009) Methyl jasmonate dramatically enhances the accumulation of phenolic acids in Salvia miltiorrhiza hairy root cultures. Physiol Plant 137:1-9. https://doi.org/10.1111/j.1399-3054.2009.01257.x

110. Xiao Y, Gao S, Di P, Chen J, Chen W, Zhang L (2010) Lithospermic acid B is more responsive to silver ions $\left(\mathrm{Ag}^{+}\right)$than rosmarinic acid in Salvia miltiorrhiza hairy root cultures. Biosci Rep 30:33-40. https://doi.org/10.1042/BSR20080124

111. Xing B, Liang L, Liu L, Hou Z, Yang D, Yan K, Zhang X, Liang Z (2018a) Overexpression of $\mathrm{SmbHLH148}$ induced biosynthesis of tanshinones as well as phenolic acids in Salvia miltiorrhiza hairy roots. Plant Cell Rep 37:1681-1692. https://doi.org/10.1007/s00299-018-2339-9

112. Xing B, Yang D, Guo W, Liang Z, Yan X, Zhu Y, Liu Y (2015) $\mathrm{Ag}^{+}$as a more effective elicitor for production of tanshinones than phenolic acids in Salvia miltiorrhiza hairy roots. Molecules 20:309324. https://doi.org/10.3390/molecules20010309

113. Xing B, Yang D, Liu L, Han R, Sun Y, Liang Z (2018b) Phenolic acid production is more effectively enhanced than tanshinone production by methyl jasmonate in Salvia miltiorrhiza hairy roots. Plant Cell Tissue Organ Cult 134:119-129. https://doi.org/10.1007/s11240-018-1405-x

114. Yan Q, Shi M, Ng J, Wu JY (2006) Elicitor-induced rosmarinic acid accumulation and secondary metabolism enzyme activities in Salvia miltiorrhiza hairy roots. Plant Sci 170:853-858. https://doi.org/10.1016/j.plantsci.2005.12.004

115. Yang L, Ding G, Lin H, Cheng H, Kong Y, Wei Y, Fang X, Liu R, Wang L, Chen X, Yang C (2013) Transcriptome analysis of medicinal plant Salvia miltiorrhiza and identification of genes related to tanshinone biosynthesis. PLoS One 8:e80464. https://doi.org/10.1371/journal.pone.0080464

116. Yang N, Zhou W, Su J, Wang X, Li L, Wang L, Cao X, Wang Z (2017) Overexpression of SmMYC2 increases the production of phenolic acids in Salvia miltiorrhiza. Front Plant Sci 8:1804. https://doi.org/10.3389/fpls.2017.01804

117. Yousefian S, Lohrasebi T, Farhadpour M, Haghbeen K (2020) Production of phenolic acids in hairy root cultures of medicinal plant Mentha spicata L. in response to elicitors. Mol Biol Res Commun 
9:23-34. https://doi.org/10.22099/mbrc.2020.36031.1475

118. Zhai X, Jia M, Chen L, Zheng CJ, Rahman K, Han T, Qin LP (2016) The regulatory mechanism of fungal elicitor-induced secondary metabolite biosynthesis in medical plants. Crit Rev Microbiol 43:238-261. https://doi.org/10.1080/1040841X.2016.1201041

119. Zhang $\mathrm{CH}$, Wu JY (2003) Ethylene inhibitors enhance elicitor-induced paclitaxel production in suspension cultures of Taxus spp. cells. Enzyme Microb Technol 32:71-77. https://doi.org/10.1016/S0141-0229(02)00266-1

120. Zhang S, Yan Y, Wang B, Liang Z, Liu Y, Liu F, Qi Z (2014) Selective responses of enzymes in the two parallel pathways of rosmarinic acid biosynthetic pathway to elicitors in Salvia miltiorrhiza hairy root cultures. J Biosci Bioeng 117:645-651. https://doi.org/10.1016/j.jbiosc.2013.10.013

121. Zhang Y, Xu Z, Ji A, Luo H, Song J (2018) Genomic survey of bZIP transcription factor genes related to tanshinone biosynthesis in Salvia miltiorrhiza. Acta Pharm Sin B 8:295-305. https://doi.org/10.1016/j.apsb.2017.09.002

122. Zhao J, Lou J, Mou Y, Li P, Wu J, Zhou L (2011) Diterpenoid tanshinones and phenolic acids from cultured hairy roots of Salvia miltiorrhiza Bunge and their antimicrobial activities. Molecules 16:2259-2267. https://doi.org/10.3390/molecules16032259

123. Zhou W, Huang Q, Wu X, Zhou Z, Ding M, Shi M, Huang F, Li S, Wang Y, Kai G (2017) Comprehensive transcriptome profiling of Salvia miltiorrhiza for discovery of genes associated with the biosynthesis of tanshinones and phenolic acids. Sci Rep 7:1-12. https://doi.org/10.1038/s41598-017-10215-2

124. Elicitor-induced phenolic acids accumulation in Salvia virgata Jacq. hairy root cultures 125. Plant Cell, Tissue and Organ Culture

126. Samaneh Attaran Dowoma, Parvaneh Abrishamchia,*, Tayebeh Radjabian b, Seyed Alireza Salamic

127. ${ }^{a}$ Department of Biology, Faculty of Sciences, Ferdowsi University of Mashhad, Mashhad, Iran

128. ${ }^{b}$ Department of Biology, Faculty of Basic Sciences, Shahed University, Tehran, Iran

129. ' University of Tehran, Tehran, Iran

130. *Corresponding author at: Department of Biology, Faculty of Science, Ferdowsi University of Mashhad, Iran. Tel: +98 51 38805560; Fax: +98 5138796416

\section{Figures}


<smiles>O=C(O)/C=C/c1ccc(O)c(O)c1</smiles>

Caffeic acid

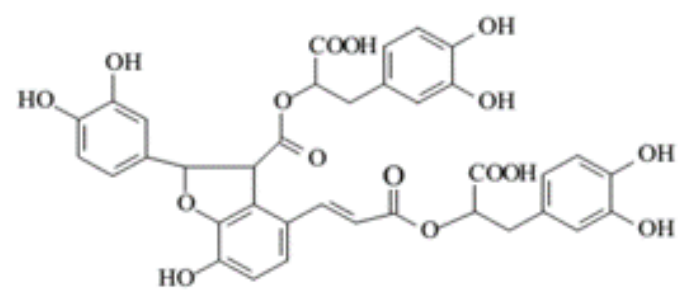

Salvianolic acid-B<smiles>O=C(/C=C/c1ccc(O)c(O)c1)OC(Cc1ccc(O)c(O)c1)C(=O)O</smiles>

Rosmarinic acid<smiles>O=C(/C=C/c1ccc(O)c(O)c1/C=C/c1ccc(O)c(O)c1)O[C@H](Cc1ccc(O)c(O)c1)C(=O)O</smiles>

Salvianolic acid-A

\section{Figure 1}

Chemical structures of caffeic acid and some of its derivatives in Salvia genus
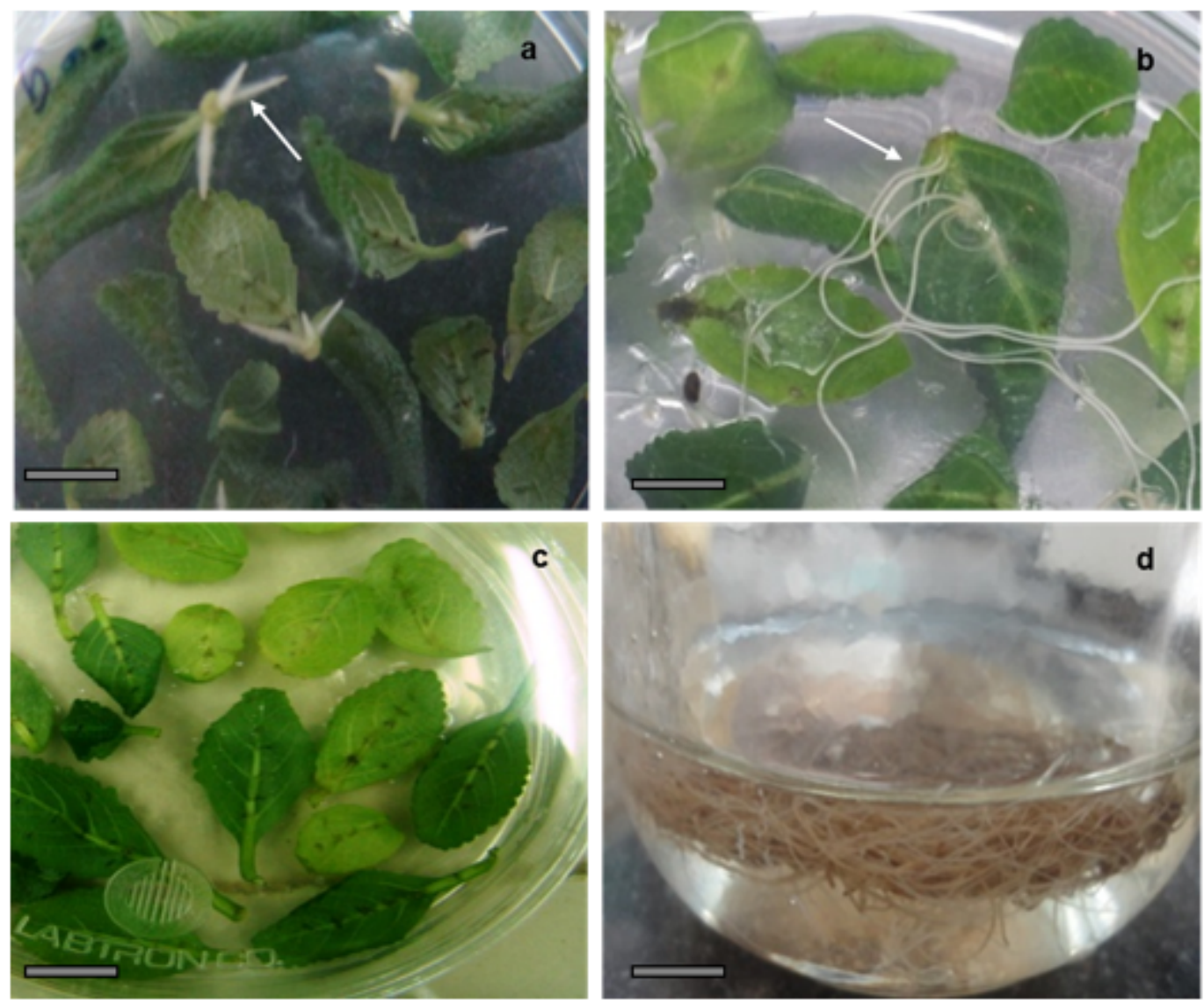


\section{Figure 2}

Induction of hairy roots from leaf explants of S. virgata on MS-based medium, a one-week and b 4 weeks after infection with A. rhizogenes strain ATCC15834. c Untransformed explants (control) after 4 weeks and $\mathrm{d} 2$-month-old hairy root cultures in 1/2 MS liquid. Arrow indicate developing hairy roots on the leaf explants. Scale bar $=1 \mathrm{~cm}$

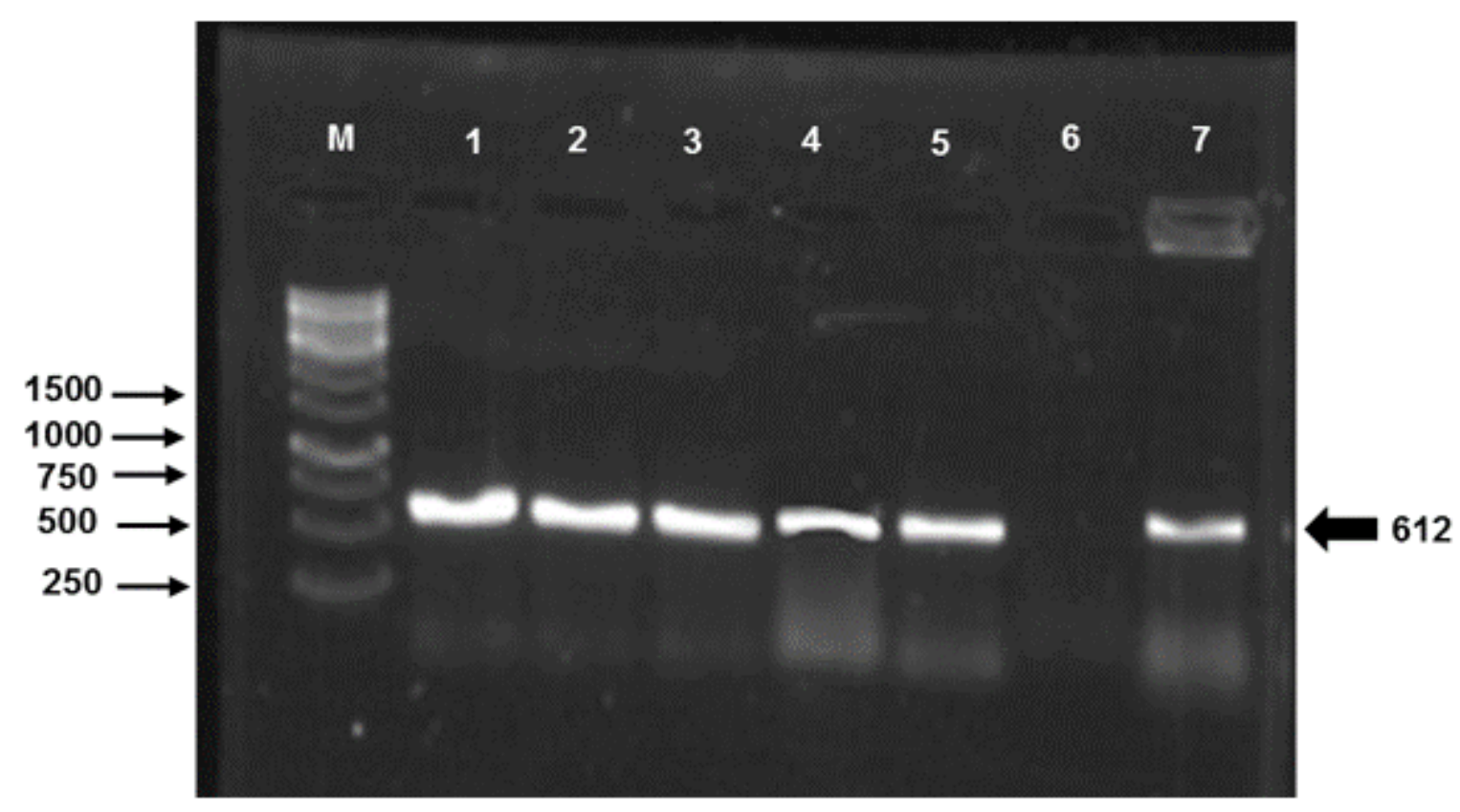

\section{Figure 3}

PCR analysis of S. virgata hairy roots transformed by different strains of A. rhizogenes. ATCC15834 strain (lane 1); R1000 strain (lane 2); A4 strain (lane 3); C58C1 strain (lane 4); GM1534 strain (lane 5); non-transformed roots (lane 6). Lane 7 is the genomic DNA from A. rhizogenes ATCC15834 strain (positive control). Lane $\mathrm{M}$ is the molecular weight marker (1 kb DNA ladder). Arrowhead shows amplified fragment of rolC (612 bp) gene 


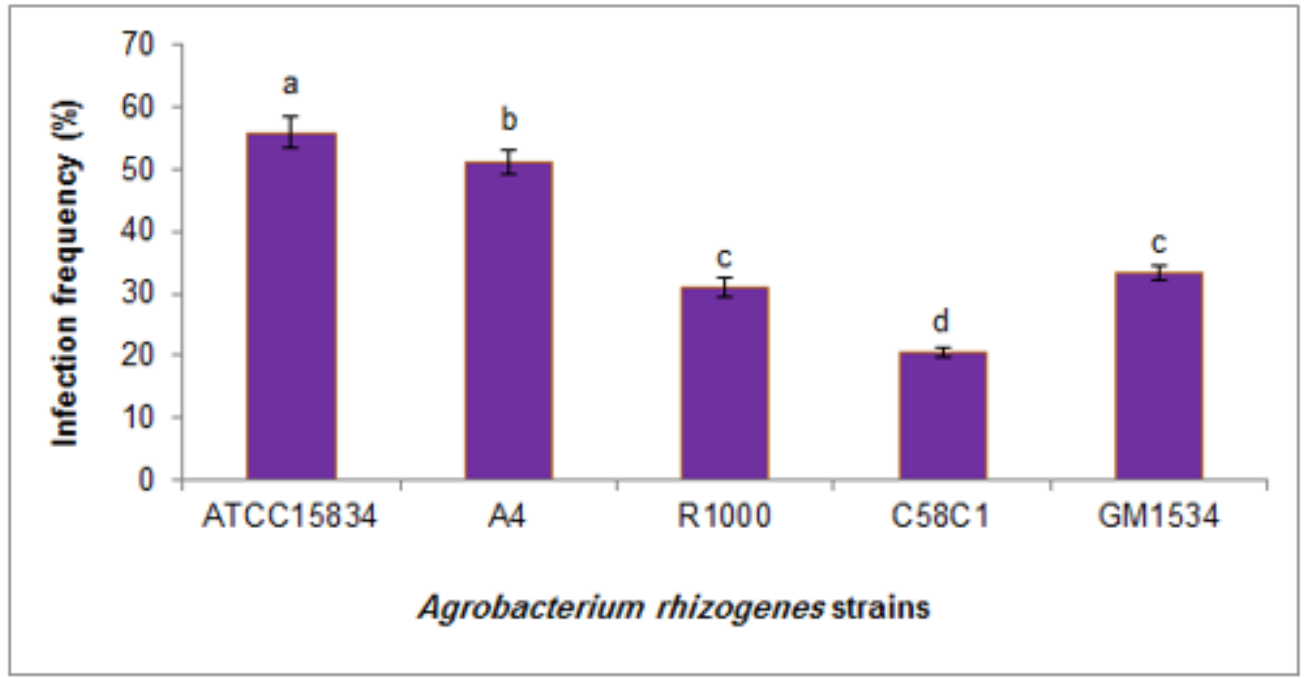

\section{Figure 4}

Hairy root induction frequency from S. virgata leaf explants. Data were collected 4 weeks after infection with different strains of $A$. rhizogenes. Each value represents mean $\pm S E$ of three replicates. Means with the same letter are not significantly different $(P \leq 0.05)$ according to Duncan's Multiple Range Test

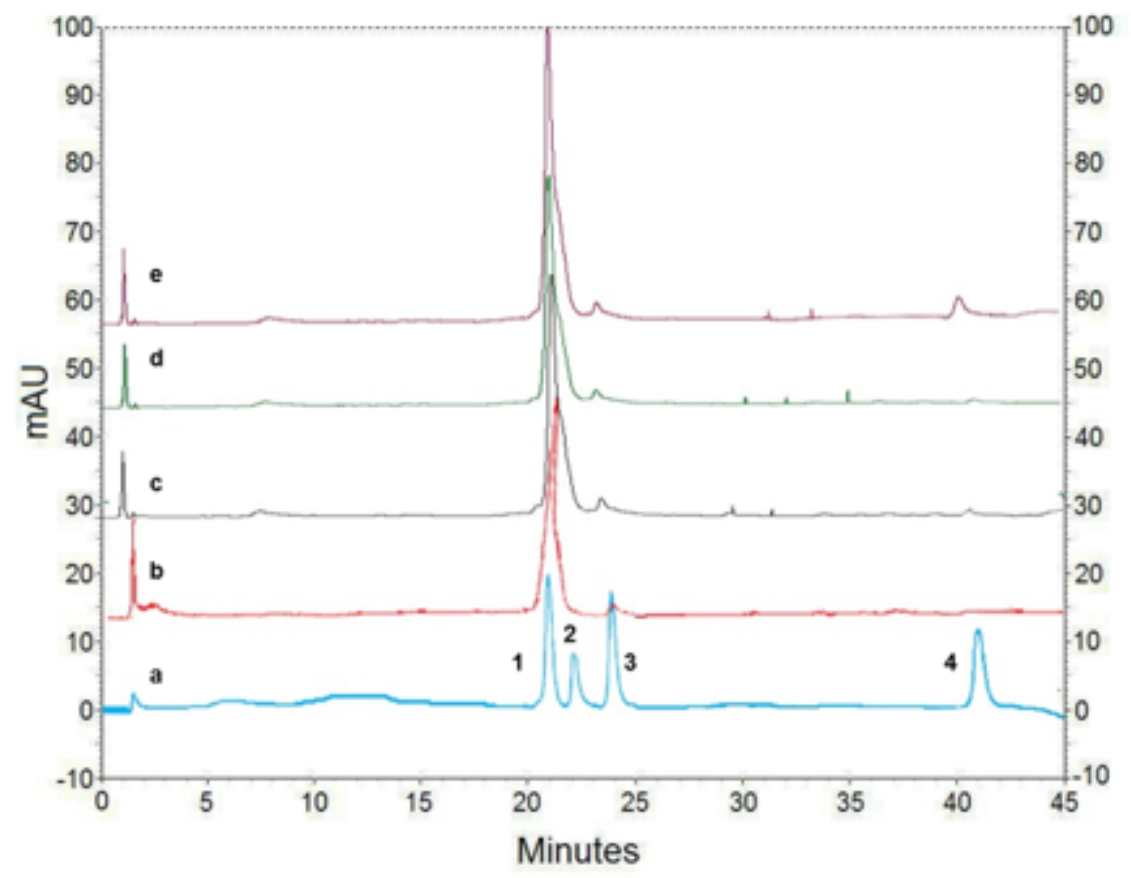

\section{Figure 5}

HPLC chromatograms of hydromethanolic extracts from S. virgata hairy roots. a Standard solution, $b$ non-elicited hairy roots (control), c hairy roots elicited with 50 ppm YE for 3 days, d hairy roots elicited with $2.5 \mathrm{ppm} \mathrm{Ag}+$ ions for 5 days, e hairy roots elicited with $22.4 \mathrm{ppm}$ MeJA for 3 days. Peak 1: rosmarinic acid; Peak 2: salvianolic acid B; Peak 3: salvianolic acid A; Peak 4: caffeic acid 

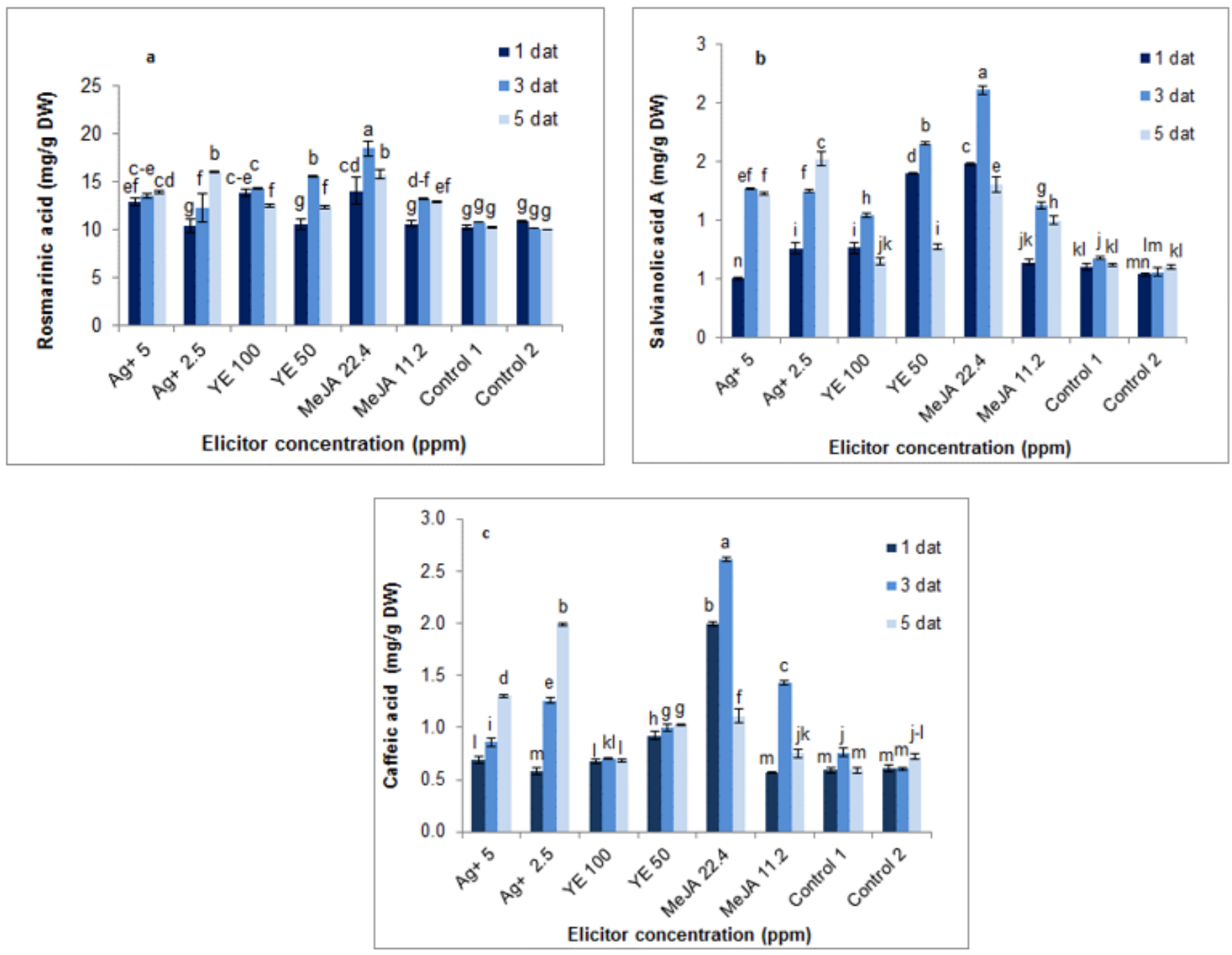

\section{Figure 6}

Effects of different concentrations of the applied elicitors on phenolic acids production in the hairy root cultures of S. virgata during periods of treatments. The data represent mean \pm SE of three replicates. The different letters denote a statistically significant difference $(P \leq 0.05)$ according to Duncan's Multiple Range Test. a Rosmarinic acid, b salvianolic acid-A, c caffeic acid. Ag+, silver ions; $Y E$, yeast extract; MeJA, methyl jasmonate; Controls 1, untreated roots; Control 2, ethanol-treated roots; dat, day after treatment

\section{Supplementary Files}

This is a list of supplementary files associated with this preprint. Click to download.

- GraphicalAbstract.png 